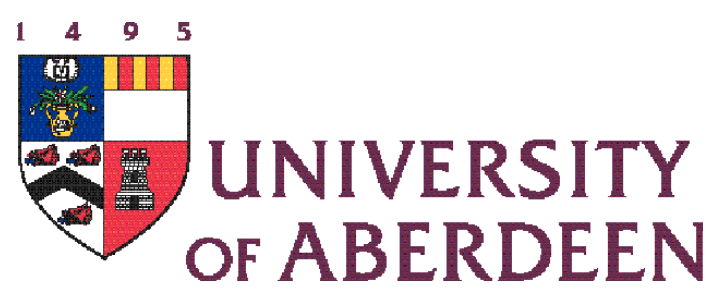

NORTH SEA STUDY OCCASIONAL PAPER

No. 139

\title{
Can Long Term Activity in the UK Continental Shelf (UKCS) Really be Transformed?
}

Professor Alexander G. Kemp

and

Linda Stephen

April, 2017

Aberdeen Centre for Research in Energy Economics and Finance (ACREEF)

(C) A.G. Kemp and Linda Stephen 
ISSN 0143-022X

\section{NORTH SEA ECONOMICS}

Research in North Sea Economics has been conducted in the Economics Department since 1973. The present and likely future effects of oil and gas developments on the Scottish economy formed the subject of a long term study undertaken for the Scottish Office. The final report of this study, The Economic Impact of North Sea Oil on Scotland, was published by HMSO in 1978. In more recent years further work has been done on the impact of oil on local economies and on the barriers to entry and characteristics of the supply companies in the offshore oil industry.

The second and longer lasting theme of research has been an analysis of licensing and fiscal regimes applied to petroleum exploitation. Work in this field was initially financed by a major firm of accountants, by British Petroleum, and subsequently by the Shell Grants Committee. Much of this work has involved analysis of fiscal systems in other oil producing countries including Australia, Canada, the United States, Indonesia, Egypt, Nigeria and Malaysia. Because of the continuing interest in the UK fiscal system many papers have been produced on the effects of this regime.

From 1985 to 1987 the Economic and Social Science Research Council financed research on the relationship between oil companies and Governments in the UK, Norway, Denmark and The Netherlands. A main part of this work involved the construction of Monte Carlo simulation models which have been employed to measure the extents to which fiscal systems share in exploration and development risks.

Over the last few years the research has examined the many evolving economic issues generally relating to petroleum investment and related fiscal and regulatory matters. Subjects researched include the economics of incremental investments in mature oil fields, economic aspects of the CRINE initiative, economics of gas developments and contracts in the new market situation, economic and tax aspects of tariffing, economics of infrastructure cost sharing, the effects of comparative petroleum fiscal systems on incentives to develop fields and undertake new exploration, the oil price responsiveness of the UK petroleum tax system, and the economics of decommissioning, mothballing and re-use of facilities. This work has been financed by a group of oil companies and Scottish Enterprise, Energy. The work on CO2 Capture, EOR and storage was financed by a grant from the Natural Environmental Research Council (NERC) in the period $2005-2008$.

For 2017 the programme examines the following subjects:
a. Transfer of Both Mature Assets and Decommissioning Tax Credit
b. Detailed Review of Guidance Note on Tax Treatment of Decommissioning for the Extractive Industries, UN Tax Committee, Sub-Committee on Extractive Industries
c. Economics of Small Pools with Particular Reference to the UKCS
d. Tax Allowances, Subsidies and State Aids
e. Economics of Shale Gas in the UK
f. Long Term Prospects for Activity in the UKCS: The Late 2017 Perspective 
The authors are solely responsible for the work undertaken and views expressed. The sponsors are not committed to any of the opinions emanating from the studies.

Papers are available from:

The Secretary (NSO Papers)
University of Aberdeen Business School
Edward Wright Building
Dunbar Street
$\begin{array}{ll}\text { Aberdeen A24 3QY } \\ \text { Tel No: } & \text { (01224) } 273427 \\ \text { Fax No: } & \text { (01224) } 272181 \\ \text { Email: } & \text { a.g.kemp@abdn.ac.uk }\end{array}$

Recent papers published are:

OP 98 Prospects for Activity Levels in the UKCS to 2030: the 2005 Perspective

By A G Kemp and Linda Stephen (May 2005), pp. 52

$£ 20.00$

OP 99 A Longitudinal Study of Fallow Dynamics in the UKCS

By A G Kemp and Sola Kasim, (September 2005), pp. 42

$£ 20.00$

OP $100 \quad$ Options for Exploiting Gas from West of Scotland

By A G Kemp and Linda Stephen, (December 2005), pp. 70

OP 101 Prospects for Activity Levels in the UKCS to 2035 after the 2006 Budget

By A G Kemp and Linda Stephen, (April 2006) pp. 61

$£ 30.00$

OP 102 Developing a Supply Curve for $\mathrm{CO}_{2}$ Capture, Sequestration and EOR in the UKCS: an Optimised Least-Cost Analytical

Framework

By A G Kemp and Sola Kasim, (May 2006) pp. 39

OP 103 Financial Liability for Decommissioning in the UKCS: the Comparative Effects of LOCs, Surety Bonds and Trust Funds By A G Kemp and Linda Stephen, (October 2006) pp. 150

OP 104 Prospects for UK Oil and Gas Import Dependence

By A G Kemp and Linda Stephen, (November 2006) pp. 38

OP 105 Long-term Option Contracts for CO2 Emissions

By A G Kemp and J Swierzbinski, (April 2007) pp. 24

OP 106 The Prospects for Activity in the UKCS to 2035: the 2007 Perspective

By A G Kemp and Linda Stephen (July 2007) pp.56 
OP 107 A Least-cost Optimisation Model for $\mathrm{CO}_{2}$ capture

By A G Kemp and Sola Kasim (August 2007) pp.65

OP 108 The Long Term Structure of the Taxation System for the UK

Continental Shelf

By A G Kemp and Linda Stephen (October 2007) pp.116

OP 109 The Prospects for Activity in the UKCS to 2035: the 2008

Perspective

By A G Kemp and Linda Stephen (October 2008) pp.67

OP 110 The Economics of PRT Redetermination for Incremental Projects in the UKCS

By A G Kemp and Linda Stephen (November 2008) pp. 56

OP 111 Incentivising Investment in the UKCS: a Response to Supporting Investment: a Consultation on the North Sea Fiscal Regime By A G Kemp and Linda Stephen (February 2009) pp.93

OP 112 A Futuristic Least-cost Optimisation Model of $\mathrm{CO}_{2} £ 25.00$ Transportation and Storage in the UK/ UK Continental Shelf By A G Kemp and Sola Kasim (March 2009) pp.53

OP 113 The Budget 2009 Tax Proposals and Activity in the UK $£ 25.00$ Continental Shelf (UKCS)

By A G Kemp and Linda Stephen (June 2009) pp. 48

OP $\quad 114$ The Prospects for Activity in the UK Continental Shelf to 2040: the 2009 Perspective By A G Kemp and Linda Stephen (October 2009) pp. 48

OP 115 The Effects of the European Emissions Trading Scheme (EU ETS) on Activity in the UK Continental Shelf (UKCS) and $\mathrm{CO}_{2}$ Leakage By A G Kemp and Linda Stephen (April 2010) pp. 117

OP 116 Economic Principles and Determination of Infrastructure Third Party Tariffs in the UK Continental Shelf (UKCS)

By A G Kemp and Euan Phimister (July 2010) pp. 26

OP 117 Taxation and Total Government Take from the UK Continental Shelf (UKCS) Following Phase 3 of the European Emissions Trading Scheme (EU ETS)

By A G Kemp and Linda Stephen (August 2010) pp. 168

OP 118 An Optimised Illustrative Investment Model of the Economics of Integrated Returns from CCS Deployment in the UK/UKCS BY A G Kemp and Sola Kasim (December 2010) pp. 67 
OP 119 The Long Term Prospects for Activity in the UK Continental Shelf

BY A G Kemp and Linda Stephen (December 2010) pp. 48

OP 120 The Effects of Budget 2011 on Activity in the UK Continental Shelf

BY A G Kemp and Linda Stephen (April 2011) pp. 50

OP 121 The Short and Long Term Prospects for Activity in the UK Continental Shelf: the 2011 Perspective BY A G Kemp and Linda Stephen (August 2011) pp. 61

OP 122 Prospective Decommissioning Activity and Infrastructure Availability in the UKCS

BY A G Kemp and Linda Stephen (October 2011) pp. 80

OP 123 The Economics of $\mathrm{CO}_{2}$-EOR Cluster Developments in the UK Central North Sea/ Outer Moray Firth BY A G Kemp and Sola Kasim (January 2012) pp. 64

OP 124 A Comparative Study of Tax Reliefs for New Developments in the UK Continental Shelf after Budget 2012 BY A G Kemp and Linda Stephen (July 2012) pp.108

OP 125 Prospects for Activity in the UK Continental Shelf after Recent Tax Changes: the 2012 Perspective BY A G Kemp and Linda Stephen (October 2012) pp.82

OP 126 An Optimised Investment Model of the Economics of Integrated Returns from CCS Deployment in the UK/UKCS

BY A G Kemp and Sola Kasim (May 2013) pp.33

OP 127 The Full Cycle Returns to Exploration in the UK Continental Shelf

BY A G Kemp and Linda Stephen (July 2013) pp.86

OP 128 Petroleum Taxation for the Maturing UK Continental Shelf (UKCS)

BY A G Kemp, Linda Stephen and Sola Kasim (October 2014) pp.94

OP 129 The Economics of Enhanced Oil Recovery (EOR) in the UKCS and the Tax Review

BY A G Kemp and Linda Stephen (November 2014) pp.47

OP 130 Price Sensitivity, Capital Rationing and Future Activity in the UK Continental Shelf after the Wood Review

BY A G Kemp and Linda Stephen (November 2014) pp.41 
OP 131 Tax Incentives for $\mathrm{CO}_{2}$-EOR in the UK Continental Shelf BY A G Kemp and Sola Kasim (December 2014) pp. 49

OP 132 The Investment Allowance in the Wider Context of the UK Continental Shelf in 2015: A Response to the Treasury Consultation BY A G Kemp and Linda Stephen (February 2015) pp. 27

OP 133 The Economics of Exploration in the UK Continental Shelf: the 2015 Perspective

BY A G Kemp and Linda Stephen (August 2015) pp. 71

OP 134 Prospective Returns to Exploration in the UKCS with Cost Reductions and Tax Incentives

BY A G Kemp and Linda Stephen (December 2015) pp.81

OP 135 Maximising Economic Recovery from the UK Continental Shelf: A Response to the Draft DECC Consultation Strategy BY A G Kemp (January 2016) pp. 16

OP 136 Field Development Tax Incentives for the UK Continental Shelf (UKCS)

BY A G Kemp and Linda Stephen (March 2016) pp.66

OP 137 Economic and Tax Issues relating to Decommissioning in the UKCS: the 2016 Perspective BY A G Kemp and Linda Stephen (July 2016) pp.63

OP 138 The Prospects for Activity in the UKCS to 2050 under "Lower for Longer" Oil and Gas Price Scenarios, and the Unexploited Potential BY A G Kemp and Linda Stephen (February 2017) pp.86

OP 139 Can Long Term Activity in the UK Continental Shelf (UKCS) Really be Transformed?

BY A G Kemp and Linda Stephen (April 2017) pp. 30 


\section{Can Long Term Activity in the UK Continental Shelf (UKCS) Really be Transformed?}

Professor Alexander G. Kemp and Linda Stephen

$\underline{\text { Contents }}$

$\underline{\text { Page }}$

1. Introduction ............................................ 1

2. Methodology and Data.......................................2

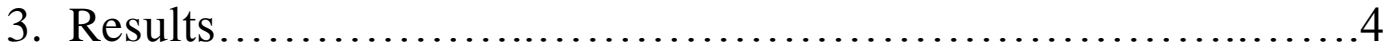

(a) Fields in Production............................ 4

(b) Oil Production........................................ 5

(c) Phasing of New Developments........................6

(d) Gas Production...................................... 7

(e) Total Hydrocarbon Production.............................8

(f) Development Expenditure.......................... 14

(g)Operating Expenditure........................... 19

(h) Decommissioning Expenditure.........................24

4. Conclusions ....................................... 29 


\title{
Can Long Term Activity in the UK Continental Shelf (UKCS) Really be Transformed?
}

\author{
Professor Alex Kemp and Linda Stephen
}

Aberdeen Centre for Research in Energy Economics and Finance (ACREEF)

\section{Introduction}

In a recent paper $^{1}$ the present authors modelled the long term prospects for activity in the UKCS under conditions which reflected the current investment climate, namely oil prices of $\$ 50$ and $\$ 60$ in real terms, the cost reductions experienced in recent years being maintained also in real terms, with both prices and costs rising annually at the general inflation rate. A key finding was the large unexploited potential remaining in 2050.

The purpose of the present paper is to examine circumstances in which this potential could be exploited. It is commonly assumed that activity levels are sensitive to oil price behaviour, but the degree to which this is the case is less clear. Similarly, cost reductions can clearly facilitate new investments, but again the extent to which this is the case is less obvious. In this paper substantial modelling is undertaken with the purpose of discovering what long term levels of activity could be obtained under assumptions which, while optimistic from the viewpoint of the investment climate, may be regarded as plausible within the current policy framework which emphasises MER UK, continued enhanced cost efficiency, and the adoption of new technologies (such as those promoted by the OGTC). In addition the study assumes that oil prices will increase in real terms in the

\footnotetext{
${ }^{1}$ The Prospects for Activity in the UKCS to 2050 under "Lower for Longer" Oil and Gas Price Scenarios, and the Unexploited Potential, North Sea Study Occasional Paper No. 138, February 2017, University of Aberdeen, pp.86
} 
long term. This continues to be the views of reputable organisations such as the IEA and EIA. The modelling assumptions are not forecasts. They are part of a scenario of possibilities.

\section{Methodology}

The present study builds on that by Kemp and Stephen (2017). In that paper financial simulation modelling, including the use of the Monte Carlo technique, was employed to project activity levels to 2050 using real oil and gas prices of $\$ 60$ and 50 pence respectively. The modelling of new discoveries was based on assumptions regarding success rates and exploration effort achieved in recent years. A long term downward trend in the effort reflecting the increasing maturity of the province was assumed, but the success rate was presumed to remain constant due to continued technological progress.

With respect to field investment and operating costs it was assumed that the reductions achieved over the past two years would be largely maintained, through a mixture of more effective cost control, technological progress, and innovation such that on average costs increased at only the general inflation rate over the period.

The comprehensive database of fields included categories of sanctioned, probable, possible, technical reserves, and new discoveries. With respect to the many fields in the category of technical reserves a cost premium of $\$ 5$ per boe on the investment costs was assumed compared to current new developments. This reflects the finding that most of them were discovered some years ago but are not yet at the stage of being actively considered for development. In turn this reflects factors such as small size, distance from infrastructure, or reservoir characteristics such as high temperature/high 
pressure or heavy oil. Annual operating costs are modelled in relation to development cost and so these are relatively high as well.

In undertaking the economic modelling it was acknowledged that capital rationing was present and an investment hurdle of post-tax NPV at 10\%/ pre-tax devex at $10 \%$ of $>0.3$ was employed. The present tax system following the 2016 Budget was incorporated into the modelling.

The results of the modelling highlighted production, development expenditure, operating expenditure, and decommissioning expenditure categorised by type of field and by main geographic areas of the UKCS.

In the present study the results of the $\$ 60,50$ pence scenario are used as the base on which to build further activity resulting from a combination of higher oil and gas prices, continuing cost control, effective collaboration, and technological progress. The oil price scenario chosen is rising real in a linear manner from $\$ 60$ in 2019 to $\$ 61.29$ in 2020, $\$ 74.19$ in 2030, $\$ 87.1$ in 2040 and $\$ 100$ in 2050 . For gas the corresponding real values are 50 pence in $2019,51.29$ pence in $2020,64.19$ pence in 2030,77 pence in 2040 , and 90 pence in 2050 .

The economic model tests the returns to the new fields and projects every year. When a field or project which failed the test under the $\$ 60,50$ pence base case but subsequently passes the hurdle at a higher price its development is triggered in the year in question. Such fields are labelled "new passes". When a field or project fails the hurdle at a higher price it is continuously carried forward to subsequent years when still higher prices become available. If it eventually passes the hurdle its development is 
triggered in the year in question. Such fields/projects are labelled "delayed passes".

The modelling also calculates the effect of higher prices on the economic limit and thus recovery from existing producing and sanctioned fields. A rising price should extend the economic limit or COP date. This effect has also been modelled and labelled "field extension".

The modelling has been undertaken separately for the five main geographic areas of the UKCS, namely the SNS, CNS/MF, NNS, W of S, and IS. The results are shown for each of these areas.

\section{Results}

(a) Fields in Production

In Chart 1 the numbers of fields in production are shown over the period to 2050 , indicating the numbers at $\$ 60$ and 50 pence and the effects of the rising price on (a) field life extensions, (b) new fields passing the hurdle, and (c) delayed fields passing the hurdle. By far the strongest effect is seen to be the large numbers of new passes.

Compared to the $\$ 60,50$ pence price scenario 78 additional fields in the category of new passes are developed in the rising price case in the period to 2050. These include 7 fields in the probable and possible categories, 50 in the category of technical reserves, and 21 new discoveries. Altogether they produce 3.85 bn boe giving an average size of 49.4 mmboe.

A further 75 fields in the category of delayed passes were also developed under the rising price case. There are 7 in the 
probable/possible category, 65 in the category of technical reserves, and 3 new discoveries. Altogether they produce 1.5 bn boe giving an average size for this group of $20 \mathrm{mmboe}$. This lower average size helps to explain why the developments were delayed.

Chart 1

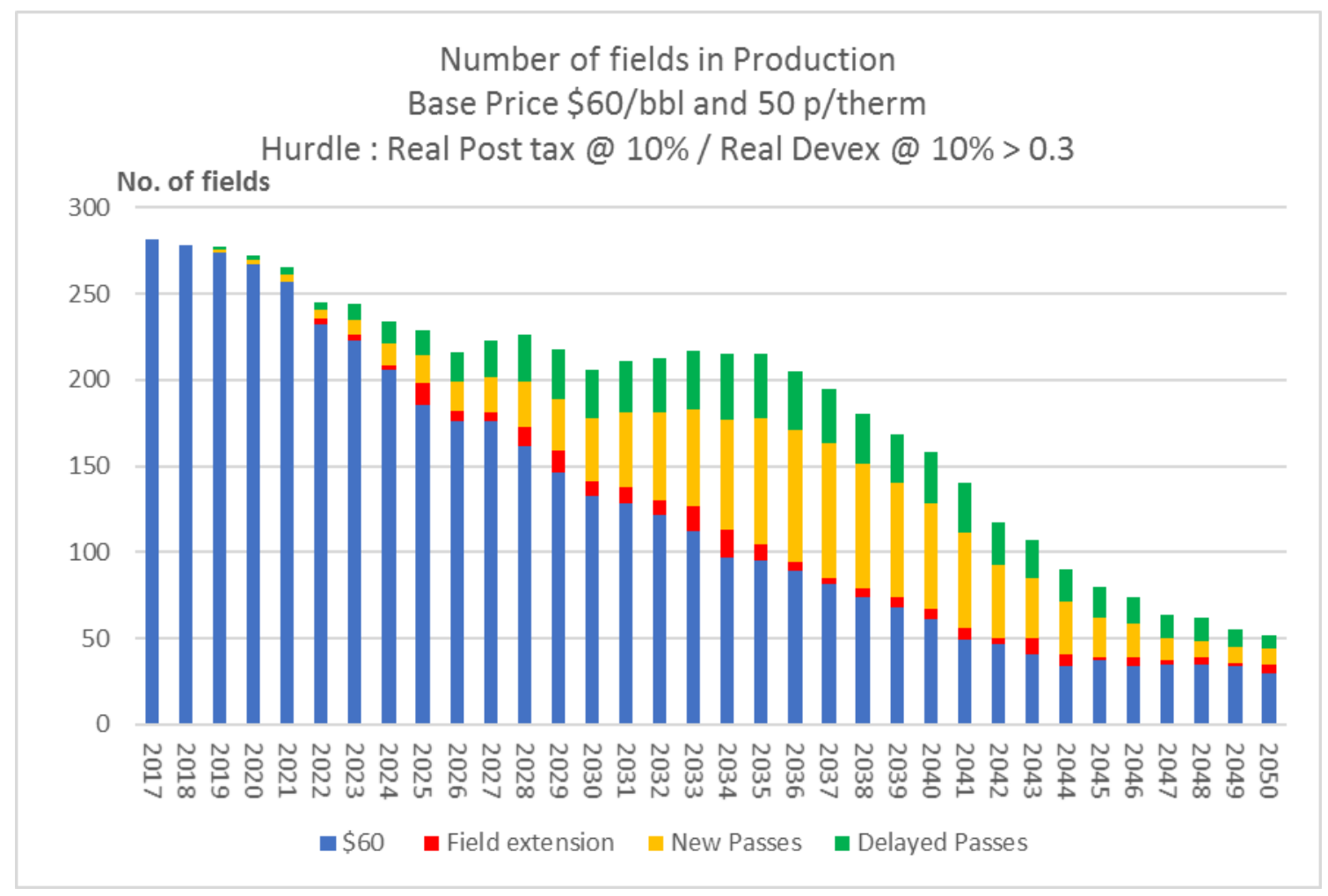

\section{(b)Oil Production}

In Chart 2 the behaviour of oil production under the various categories of fields noted above is shown. It is seen that the extra production in the period is very substantial. In total it amounts to 3.4 billion bbls (bn bbls) over the period to 2050. Around 2.6 bn bbls come from fields in the new passes category, 0.8 billion in the delayed passes category, and $68 \mathrm{mmbbls}$ from field life extensions. The effect is particularly strong in the period from 2026 to 2045 . The decline rate from 2038 is quite steep. Only significantly more new discoveries could prevent this. 
The total extra production is nearly 3.5 bn boe. Much (1.56 bn boe) comes from the development of 50 technical reserves fields in the new passes category. A further 65 technical reserves fields in the delayed passes category produce 0.44 bn boe. Fourteen probable/possible fields produce nearly 1 bn boe extra in total. New discoveries produce 0.42 bn boe of extra production in total.

Chart 2

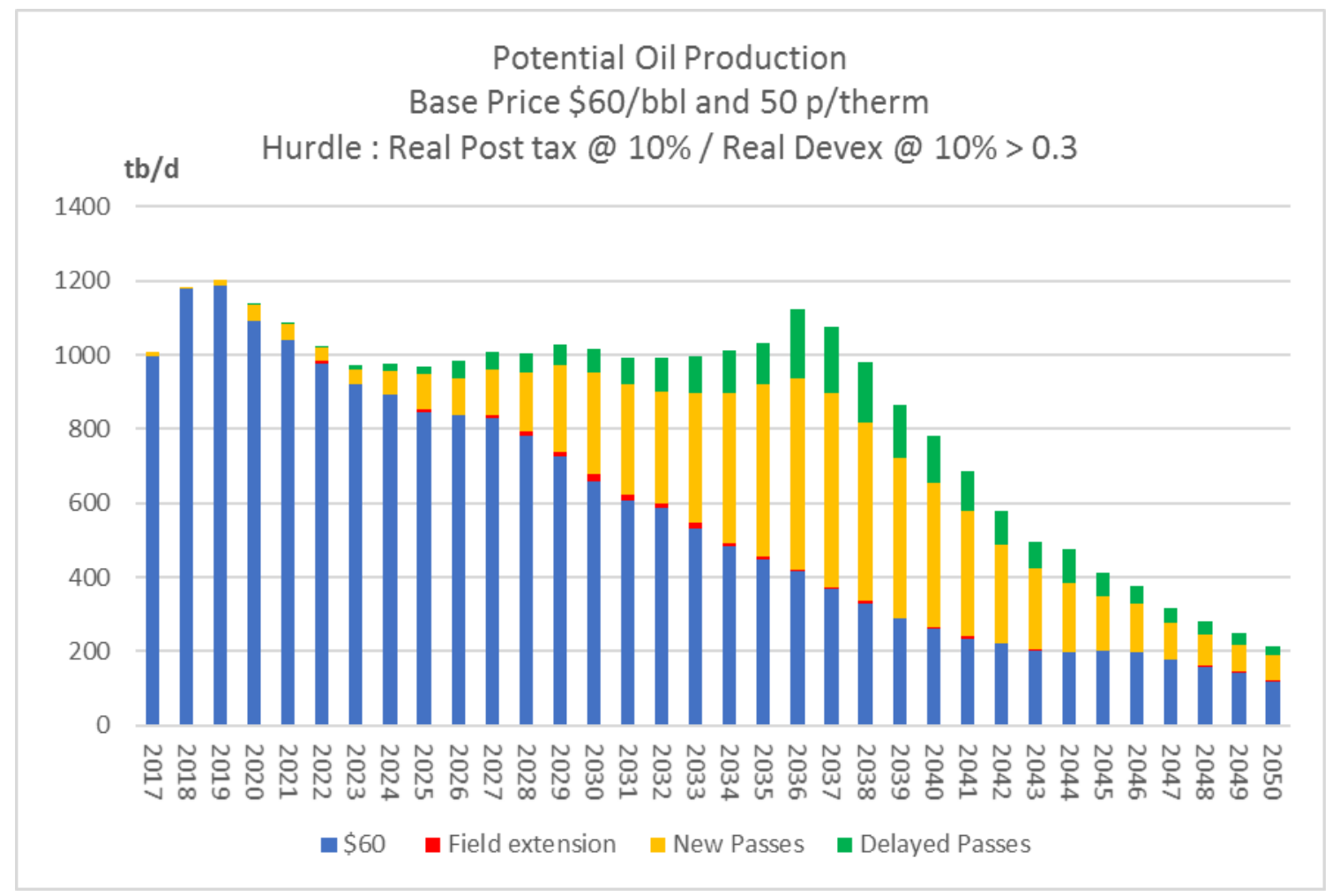

(c) Phasing of New Developments

The phasing of the extra field developments by category is shown in Chart 3. A considerable proportion of the developments in the technical reserves category is from fields where the delay in time from first assessment is very long. Thus 23 fields in this category are delayed for 
10 years or more before they become viable. Seven of these are delayed for 20 years or more before they become viable.

\section{Chart 3}

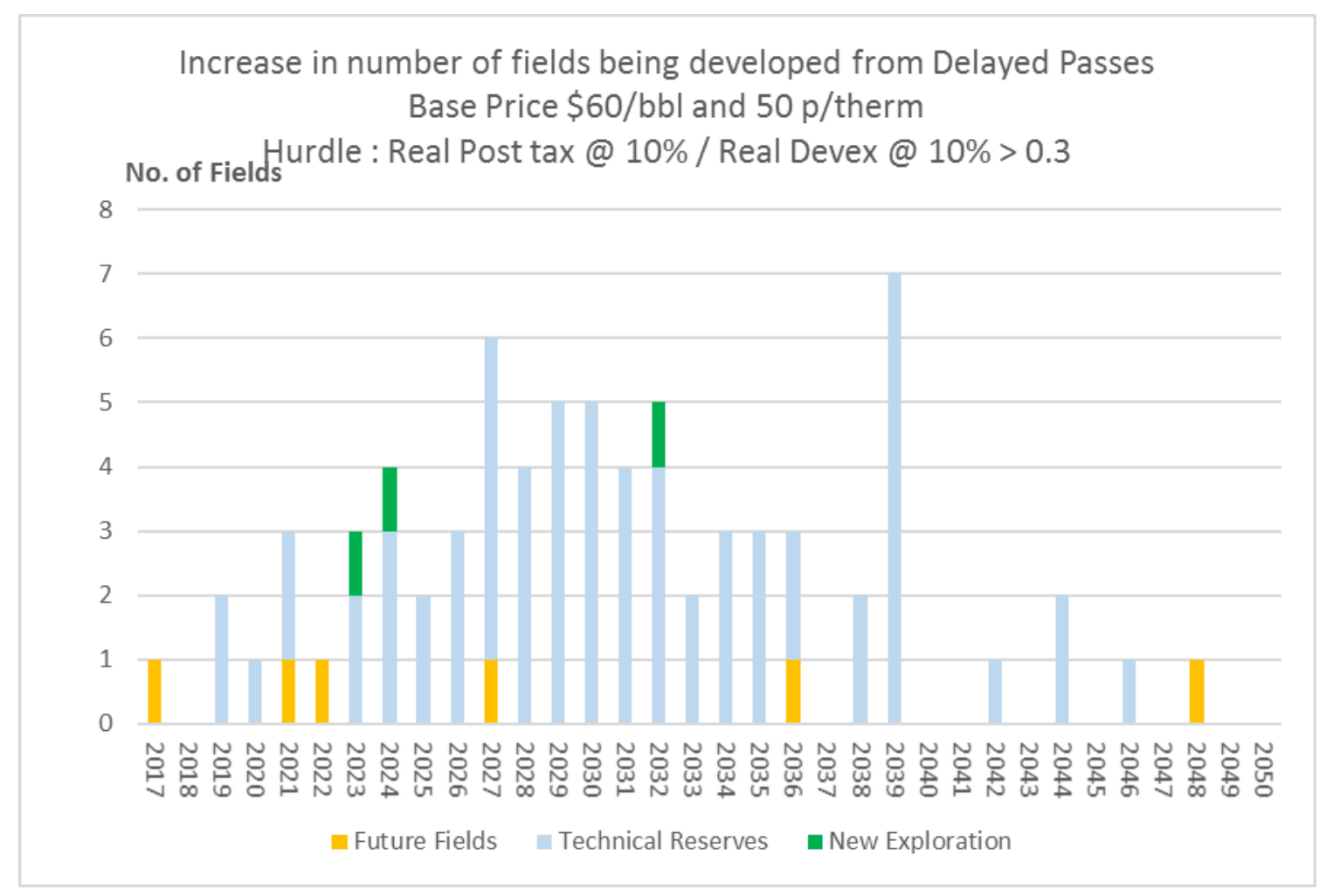

\section{(d)Gas Production}

In Chart 4 the gas production to 2050 is shown. The total extra recovery over the period is 2 billion barrels of oil equivalent (bn boe). This is much less than the extra oil recovery. Of the 2 bn boe 1.3 bn come from the development of new fields in the new passes category, 0.68 bn boe from new fields in the delayed pass category, and 32 million boe (mmboe) from field life extensions. The decline rate in total production from 2037 is particularly steep. Only significant new discoveries could moderate this. 
Chart 4

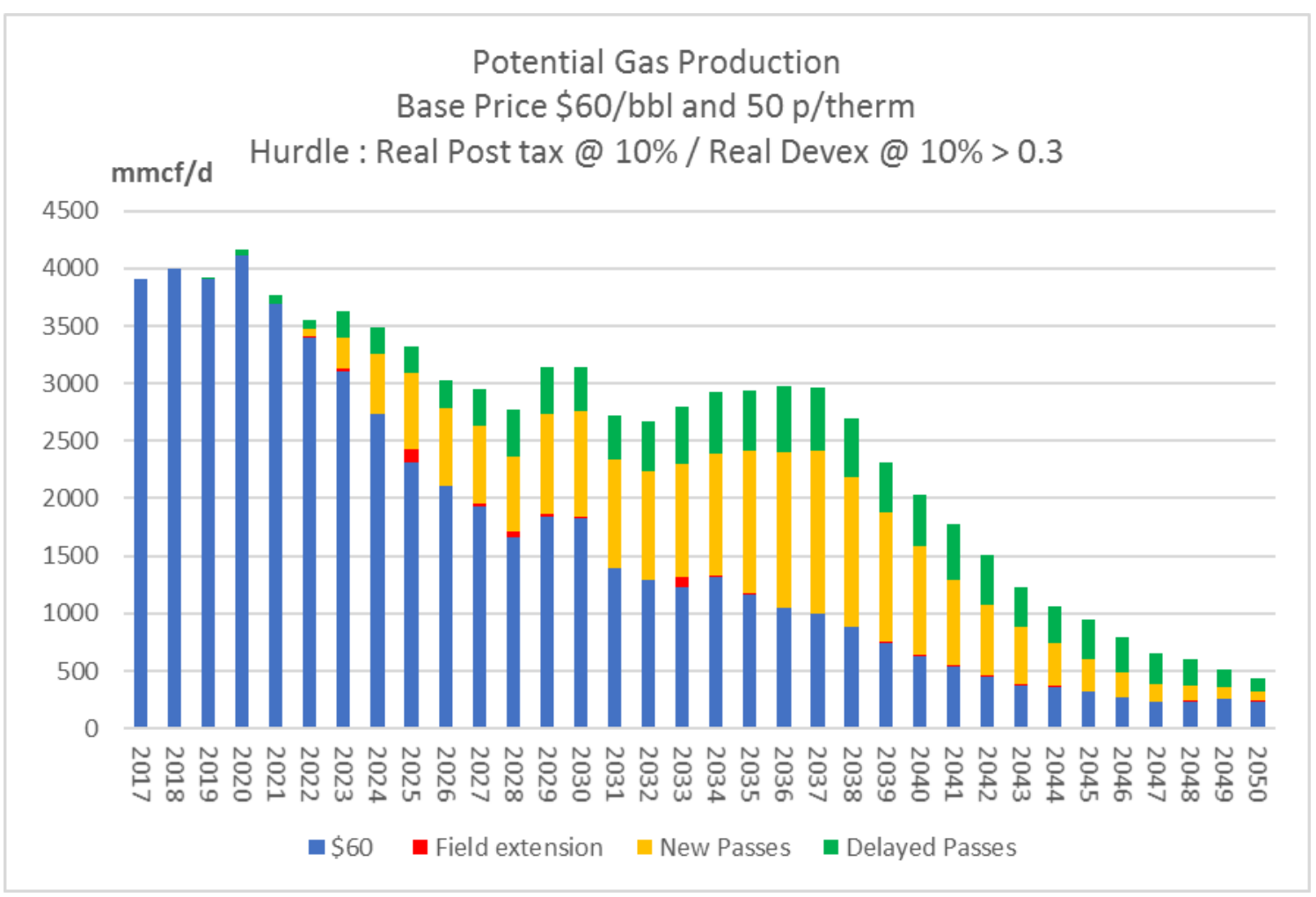

(e) Total Hydrocarbon Production

In Chart 5 total hydrocarbon production is shown. The total extra output to 2050 amounts to 5.45 bn boe. Of this 3.85 bn boe emanate from fields and projects in the new passes category, 1.5 bn boe from fields in the delayed passes category, and $102 \mathrm{mmboe}$ from field life extensions. Under the $\$ 60,50$ pence price scenario a total of 10.75 bn boe are recovered over the period. A grand total of 16.2 bn boe is comfortably within the best estimate range of ultimate recovery of 1020 bn boe made by the OGA. It is seen from Chart 5 that there is a decline from 2019 to 2028 at a mild pace followed by modestly rising output to 2036-2037, after which production falls at a rapid rate. Only significant new discoveries can prevent this. Even with higher prices there are not enough undeveloped fields to make a worthwhile addition to the production profile. 
Chart 5

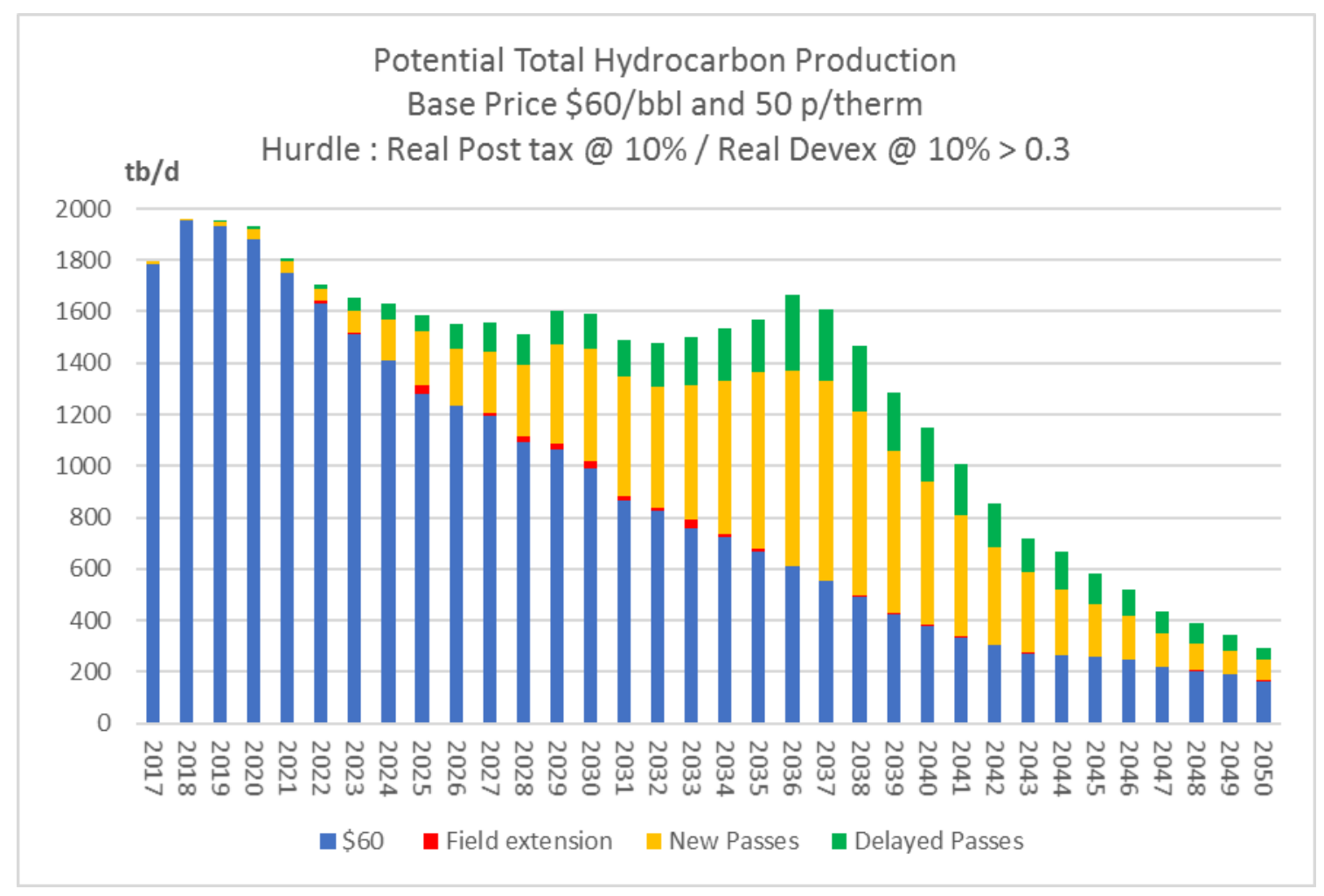

In Charts 6 and 7 the extra production from field extensions are shown. Most of the 102 mmboe emanates from sanctioned fields. The CNS accounts for nearly half the total, with other significant contributions being attributable to the NNS and W of S regions. 


\section{Chart 6}

Change in Potential Hydrocarbon Production from Field Extension Base Price $\$ 60 / \mathrm{bbl}$ and $50 \mathrm{p} /$ therm

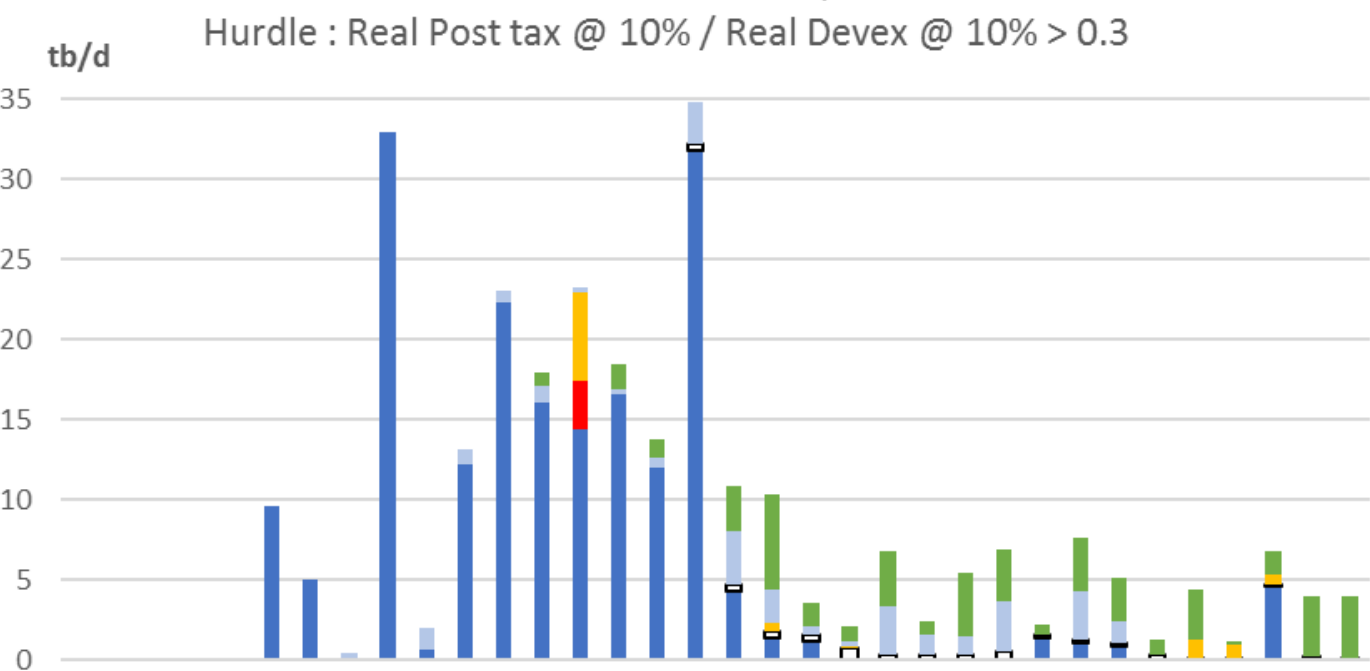

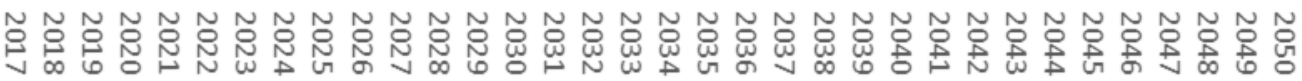
- Sanctioned

\section{Chart 7}

Change in Potential Hydrocarbon Production from Field Extension Base Price $\$ 60 / \mathrm{bbl}$ and $50 \mathrm{p} /$ therm 
In Charts 8 and 9 the extra production from fields in the new passes category are shown. The results show that significant increases in oil/gas prices from the $\$ 60,50$ pence levels are required before substantial increases in output can be achieved. Of the 3.85 bn boe extra recovery achieved as much as 2.54 bn boe comes from fields in the category of technical reserves. Of the total in the category of new passes as much as 1.55 bn boe extra production comes from the $\mathrm{W}$ of $\mathrm{S}$ region, indicating the high degree of price sensitivity of activity in this region. The extra production from the CNS at 1.22 bn boe is also very significant.

\section{Chart 8}

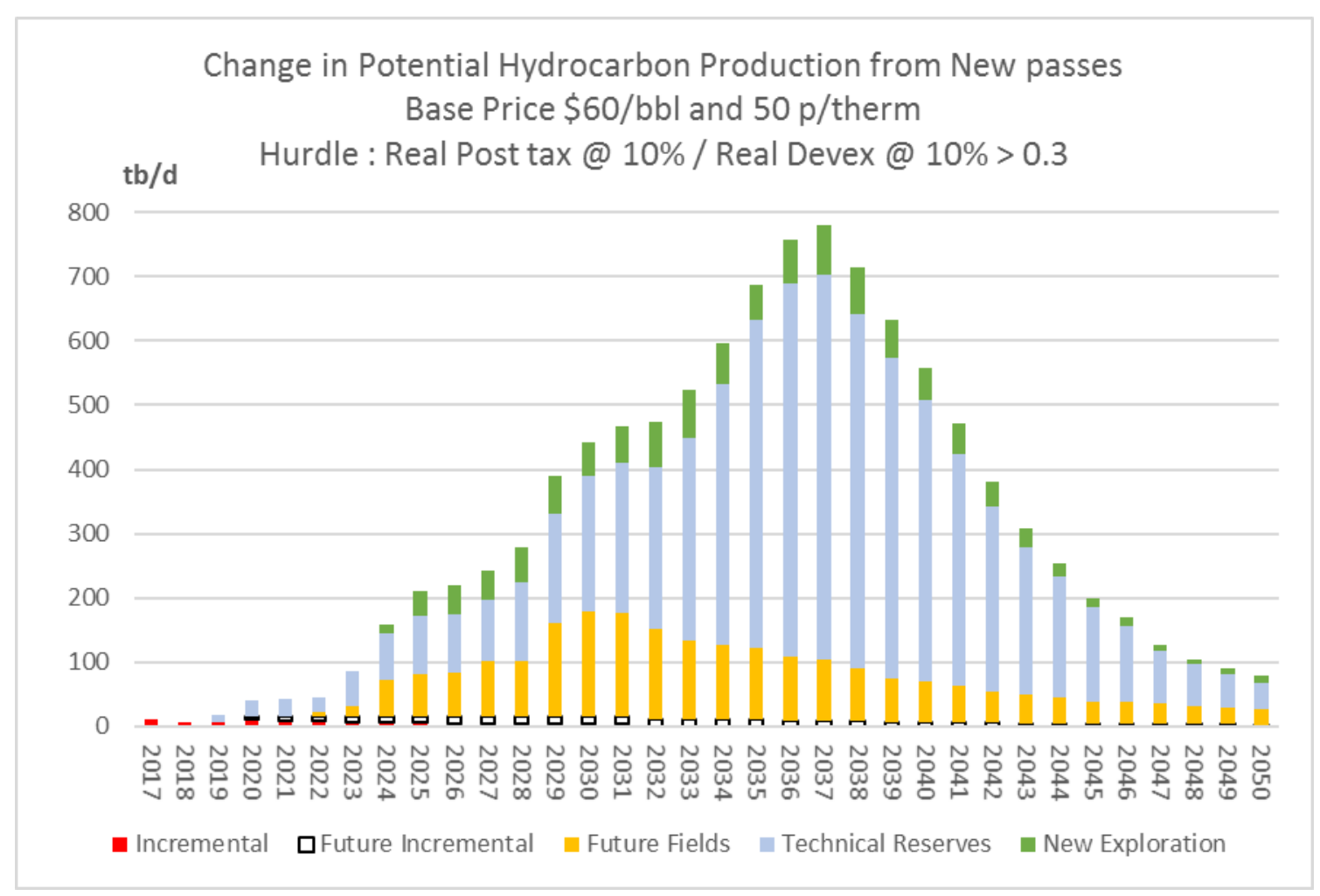


Chart 9

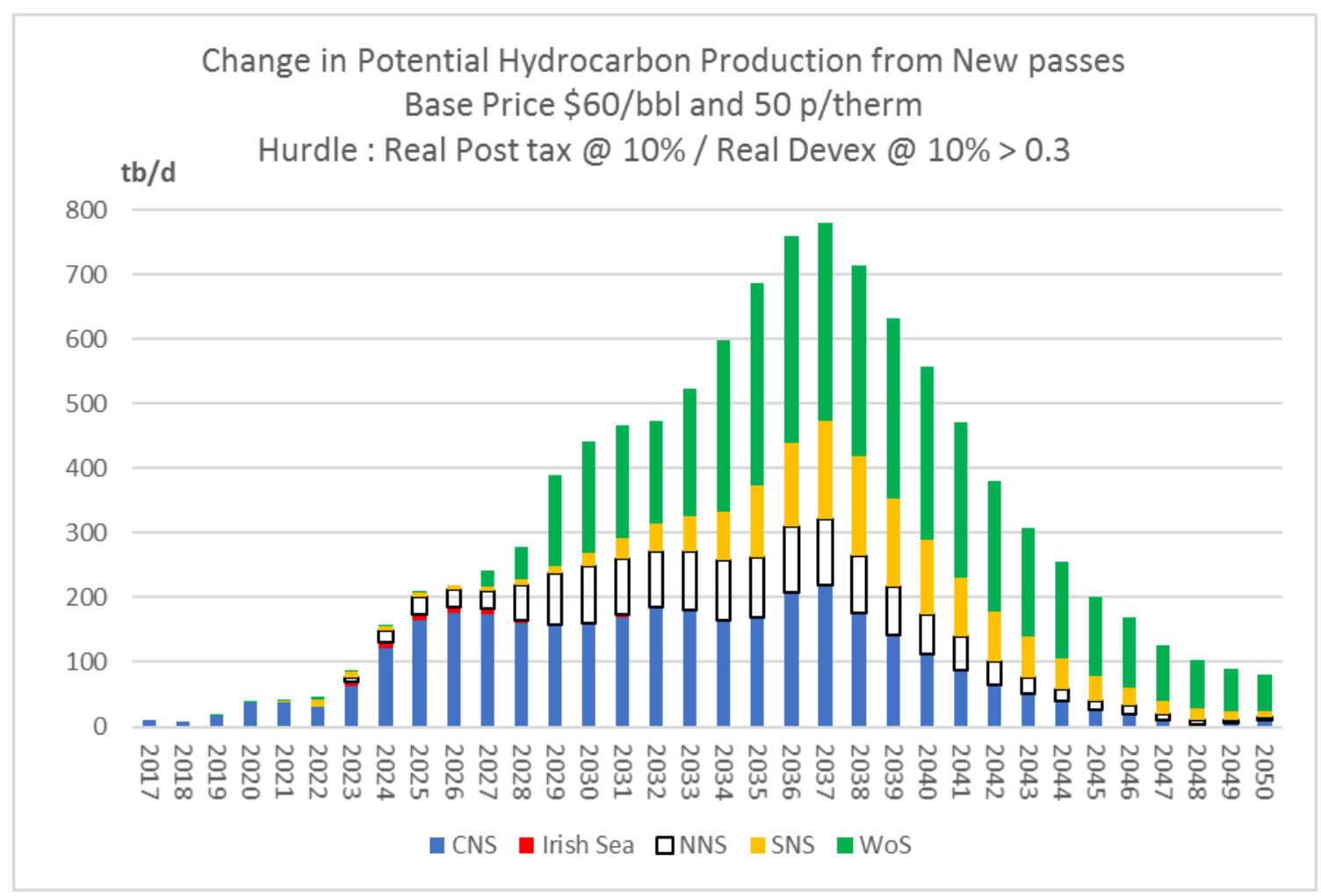

In Charts 10 and 11 the extra production form fields in the delayed passes category are shown. The total extra recovery is 1.5 bn boe of which 1 bn boe comes from fields in the category of technical reserves. Geographically, there is extra production of 490 mmboe from the CNS, 363 mmboe from the $\mathrm{W}$ of S, 402 mmboe from the NNS, and 153 mmboe from the SNS. 
Chart 10

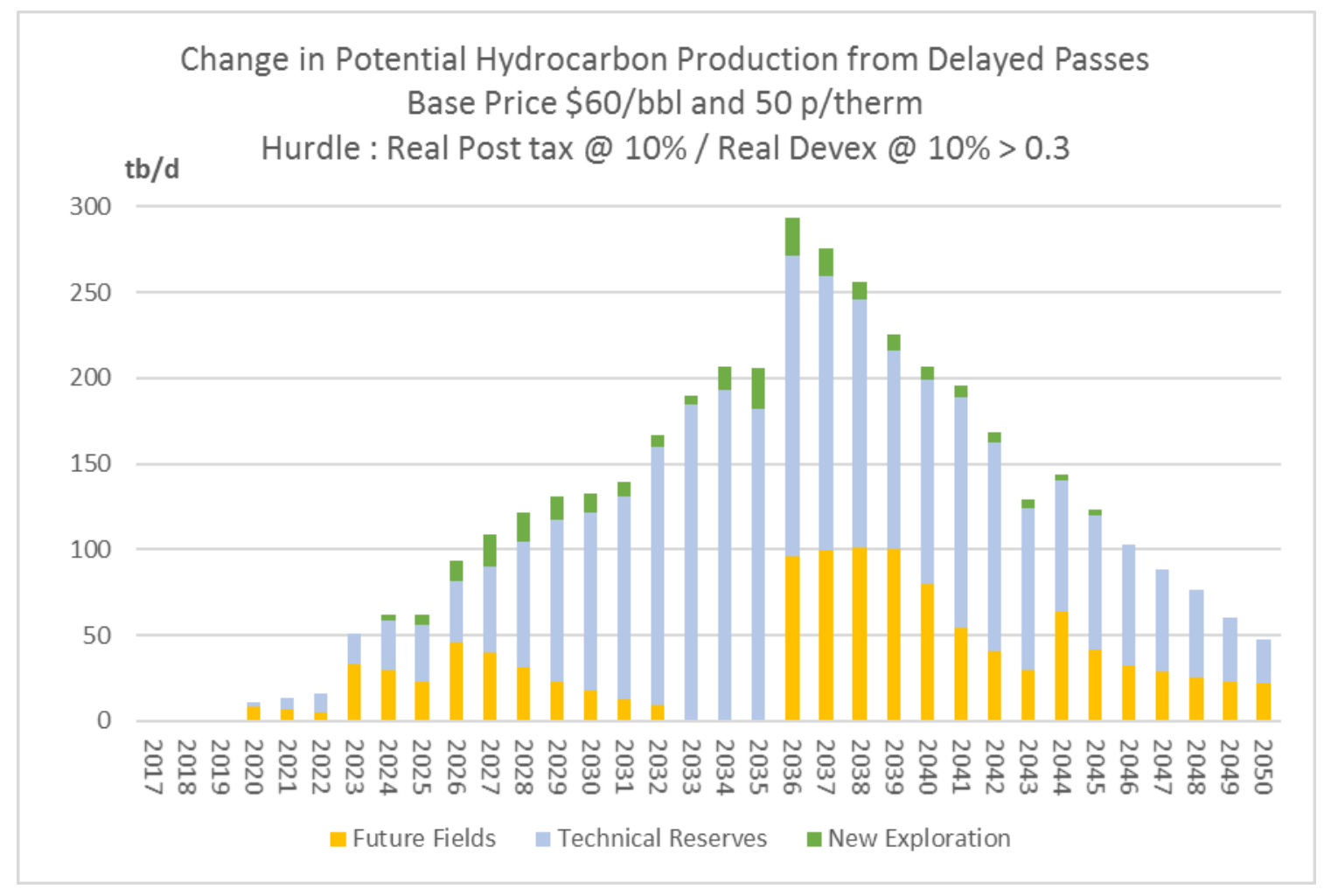

Chart 11

Change in Potential Hydrocarbon Production from Delayed Passes

Base Price $\$ 60 / \mathrm{bbl}$ and $50 \mathrm{p} /$ therm

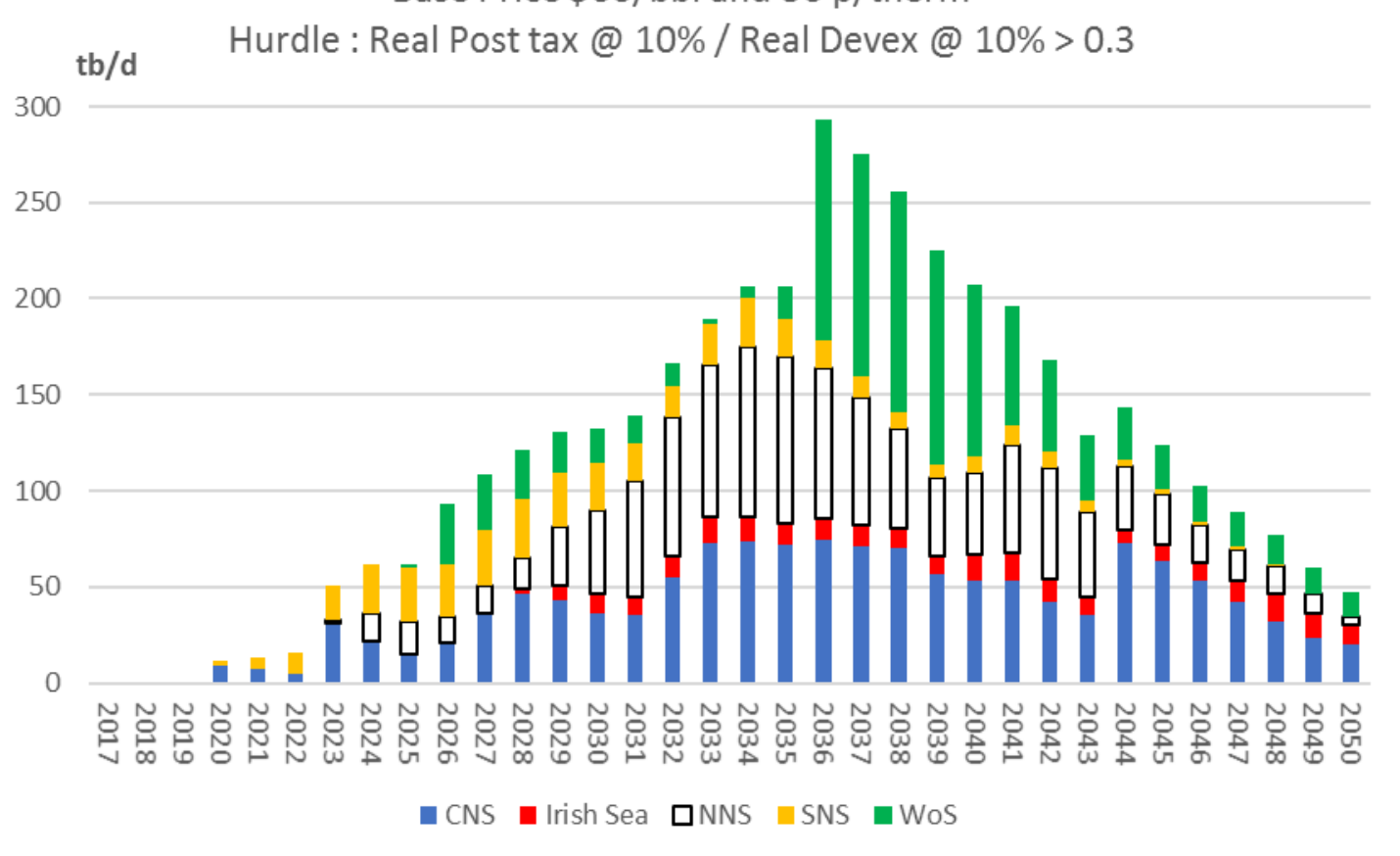




\section{(f) Development Expenditure}

In Chart 12 total development expenditures to 2050 are shown. In the base case with prices of $\$ 60$ and 50 pence the cumulative development expenditure is $£ 89.3$ bn at 2017 prices. The overall increase under the rising price scenario is $£ 94.1$ billion. Of this $£ 63.5$ billion comes from fields and projects in the new passes category, and $£ 30.6$ bn from fields and projects in the delayed passes category. The remainder emanates from sanctioned fields plus current and future incremental projects (Chart 13). Most of the field life extension investments are in the CNS (Chart 14). The rapid decline in overall development expenditure after 2034 can only be moderated by further new discoveries.

Chart 12

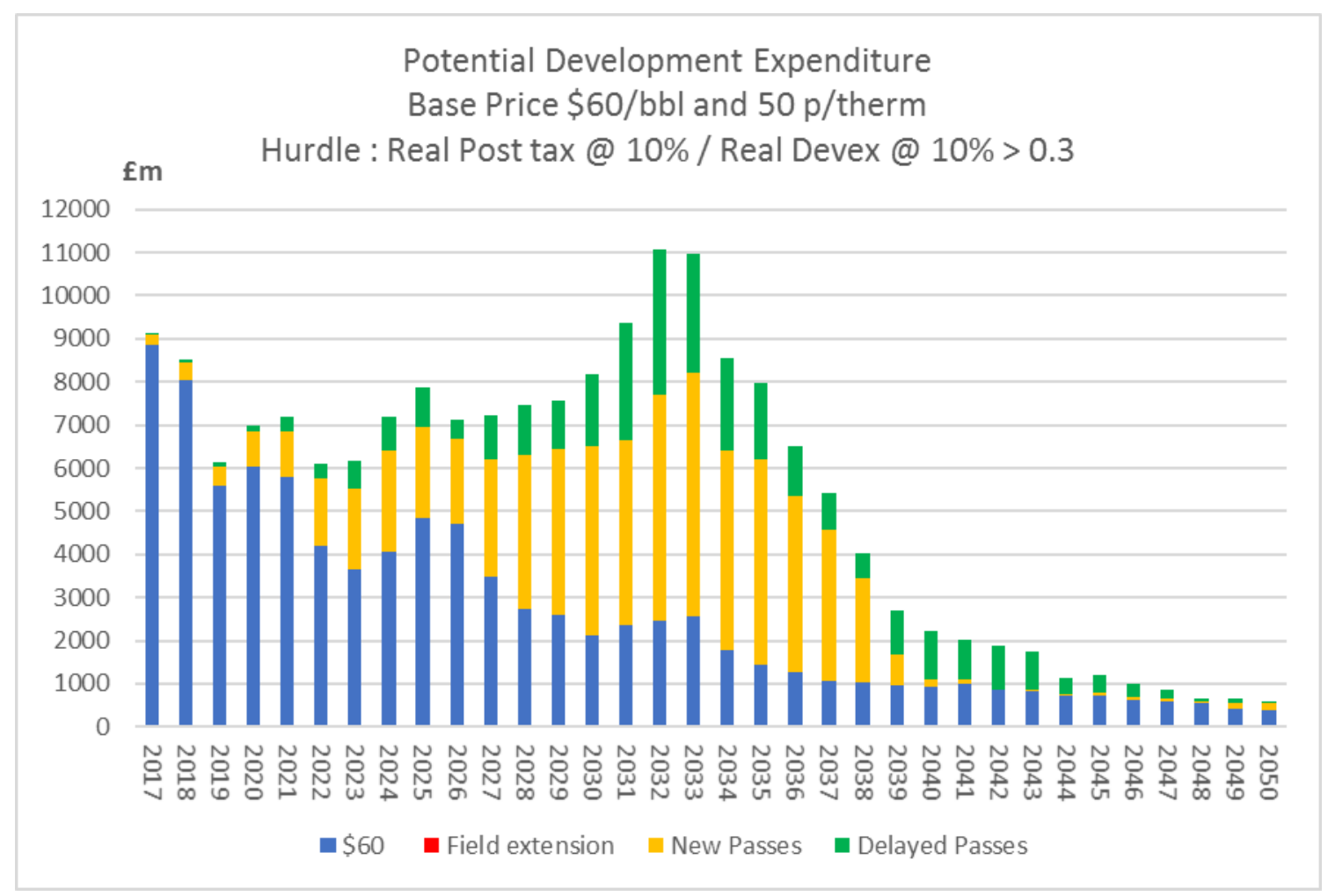




\section{Chart 13}

Change in Potential Development Expenditure from Field Extension Base Price $\$ 60 / \mathrm{bbl}$ and $50 \mathrm{p} /$ therm

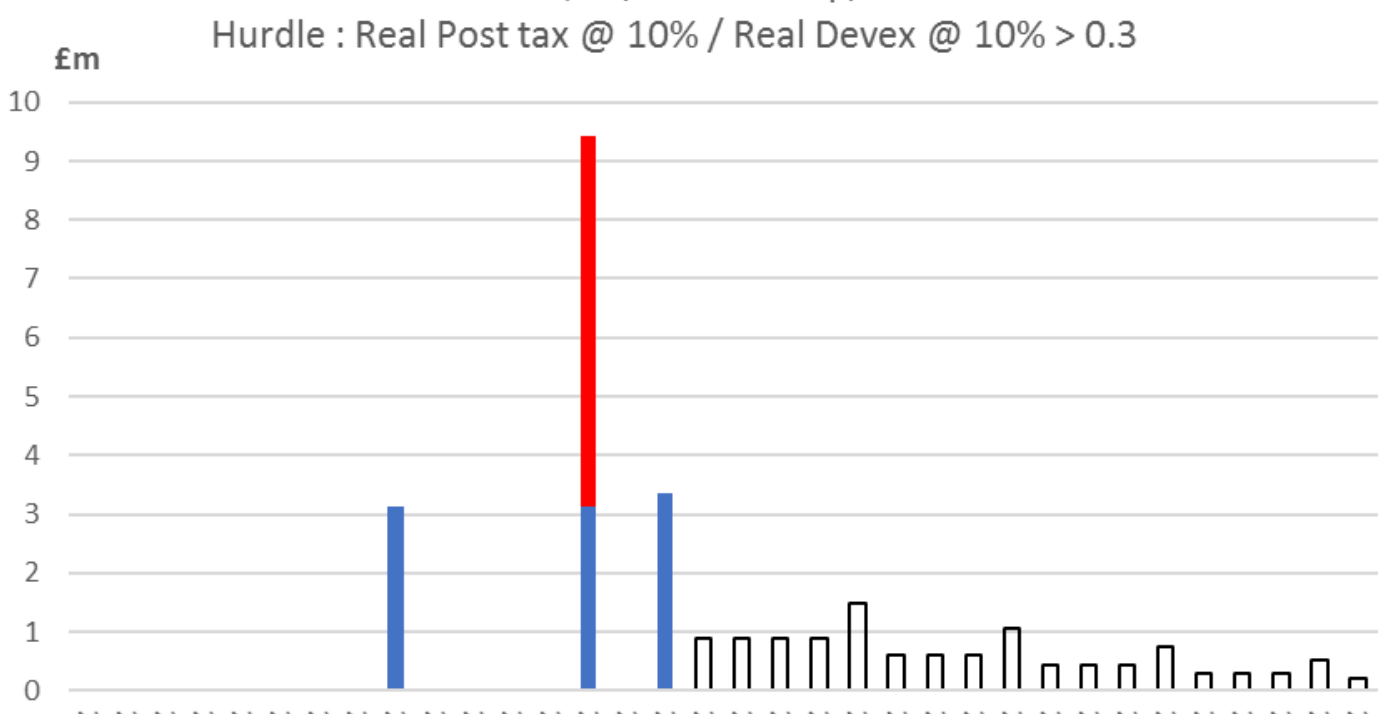

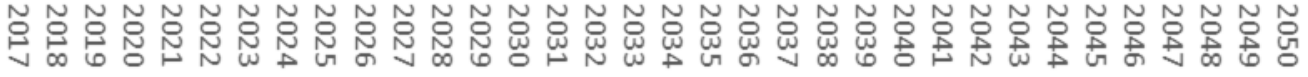

\section{Chart 14}

Change in Potential Development Expenditure from Field Extension Base Price $\$ 60 / \mathrm{bbl}$ and $50 \mathrm{p} /$ therm

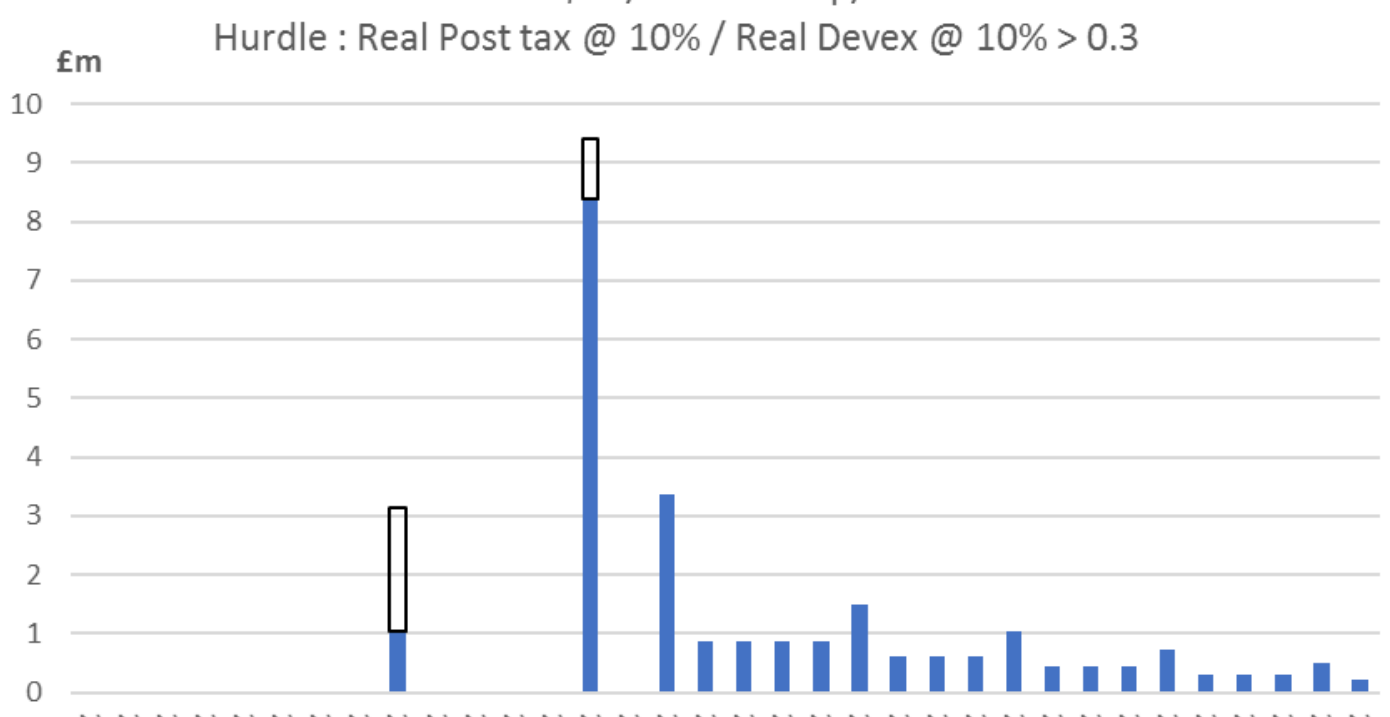

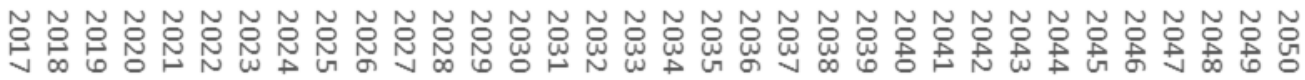
$\square$ CNS $\square$ NNS 
In Chart 15 the extra development expenditure on fields in the new passes category is shown, disaggregated by type. Probable and possible fields contribute $£ 9.8$ bn over the period. Technical reserves contribute over $£ 44$ bn, and new discoveries over $£ 8$ bn. Incremental projects (current plus future) contribute $£ 1.6 \mathrm{bn}$. The overall total of $£ 63.5 \mathrm{bn}$ constitutes a major contribution to the supply chain.

\section{Chart 15}

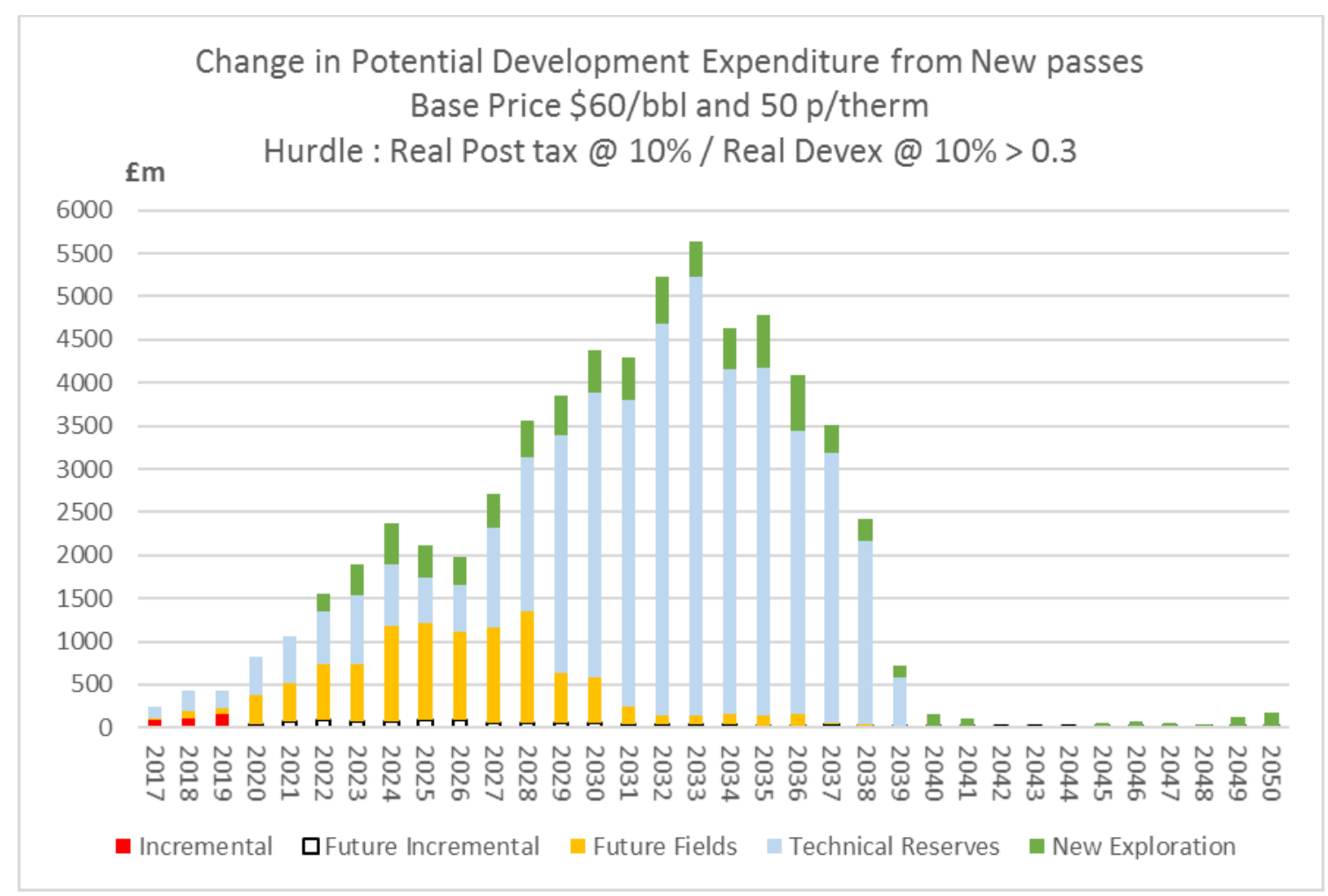

In Chart 16 the geographic distribution of development expenditure in the new passes category is shown. Around $£ 20.5$ bn occurs in the CNS, and $£ 25$ bn in the $\mathrm{W}$ of $\mathrm{S}$ region which is clearly the largest component in the total. In the NNS the increased expenditure totals $£ 9.8$ bn and in the SNS it amounts to $£ 7.9 \mathrm{bn}$. 
Chart 16

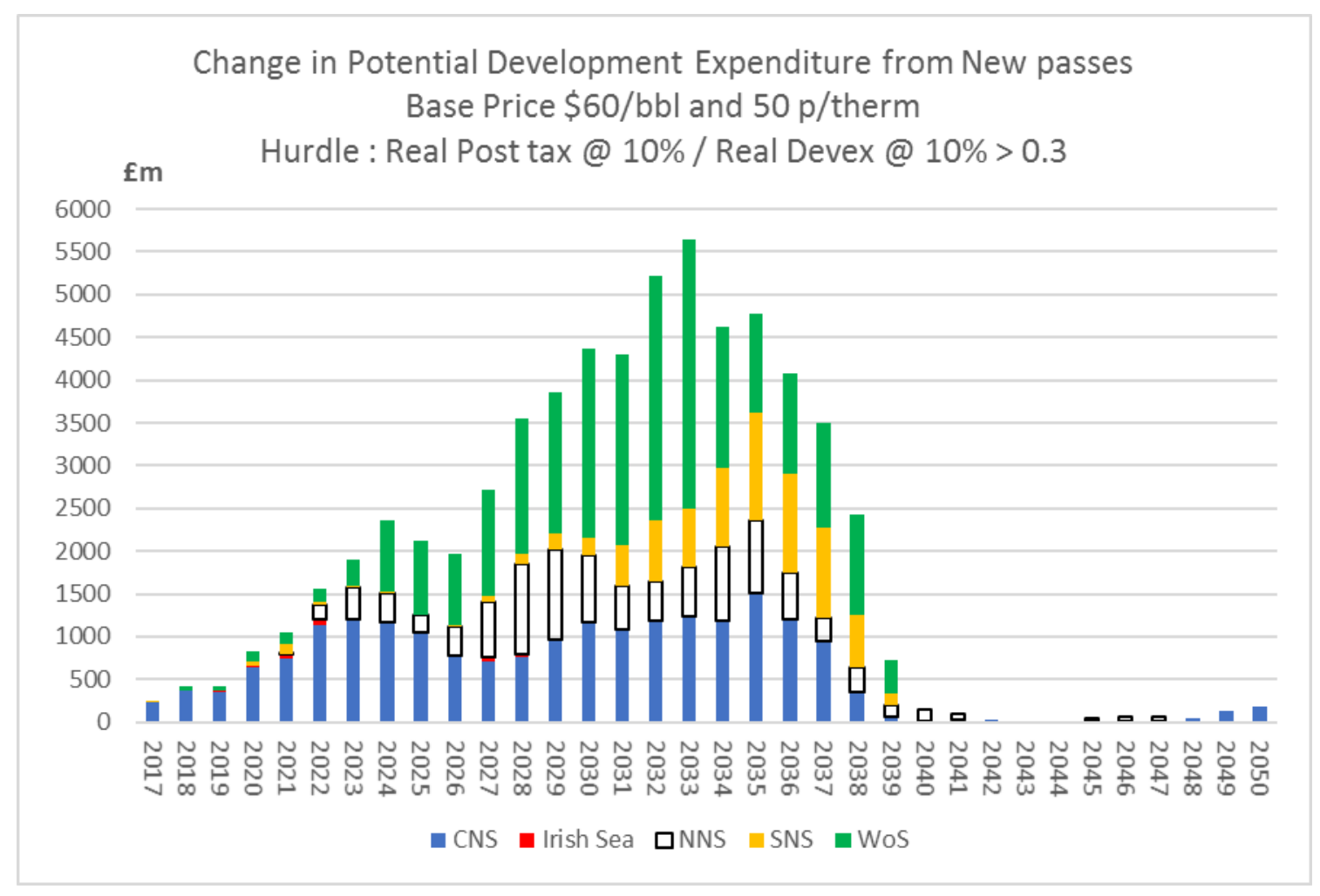

In Chart 17 the extra development expenditure from delayed passes is shown broken down by category. Of the total of $£ 30.6 \mathrm{bn}$, probable and possible fields contribute $£ 8.2$ bn, while technical reserves contribute $£ 20.8$ bn. New discoveries contribute $£ 1.6$ bn. The geographic distribution of the increased investment in fields in the delayed passes category is shown in Chart 18. It is seen that $£ 10$ bn occurs in the CNS, $£ 7$ bn in the W of S, $£ 9.1$ bn in the NNS, and $£ 2.5$ bn in the SNS. 
Chart 17

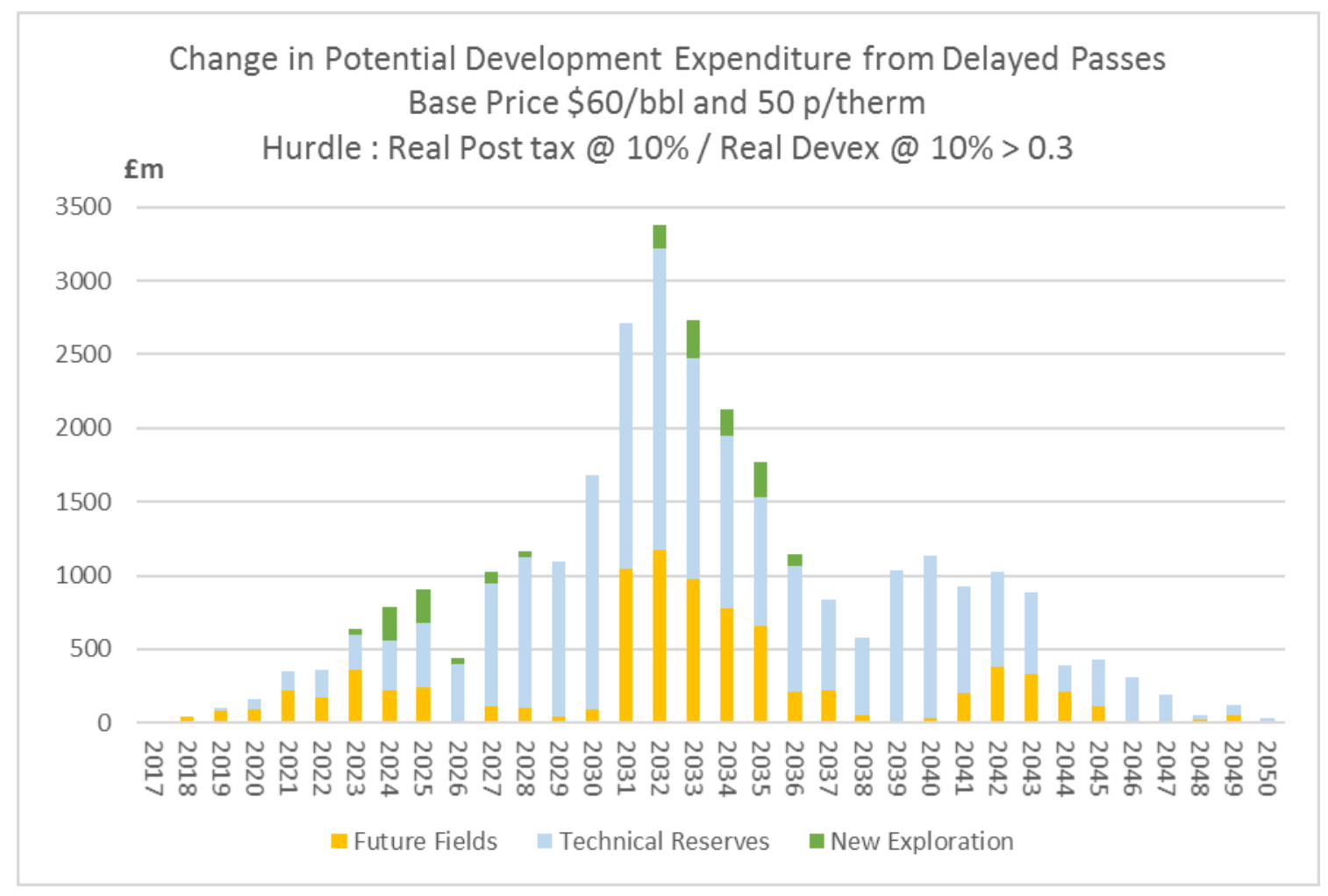

Chart 18

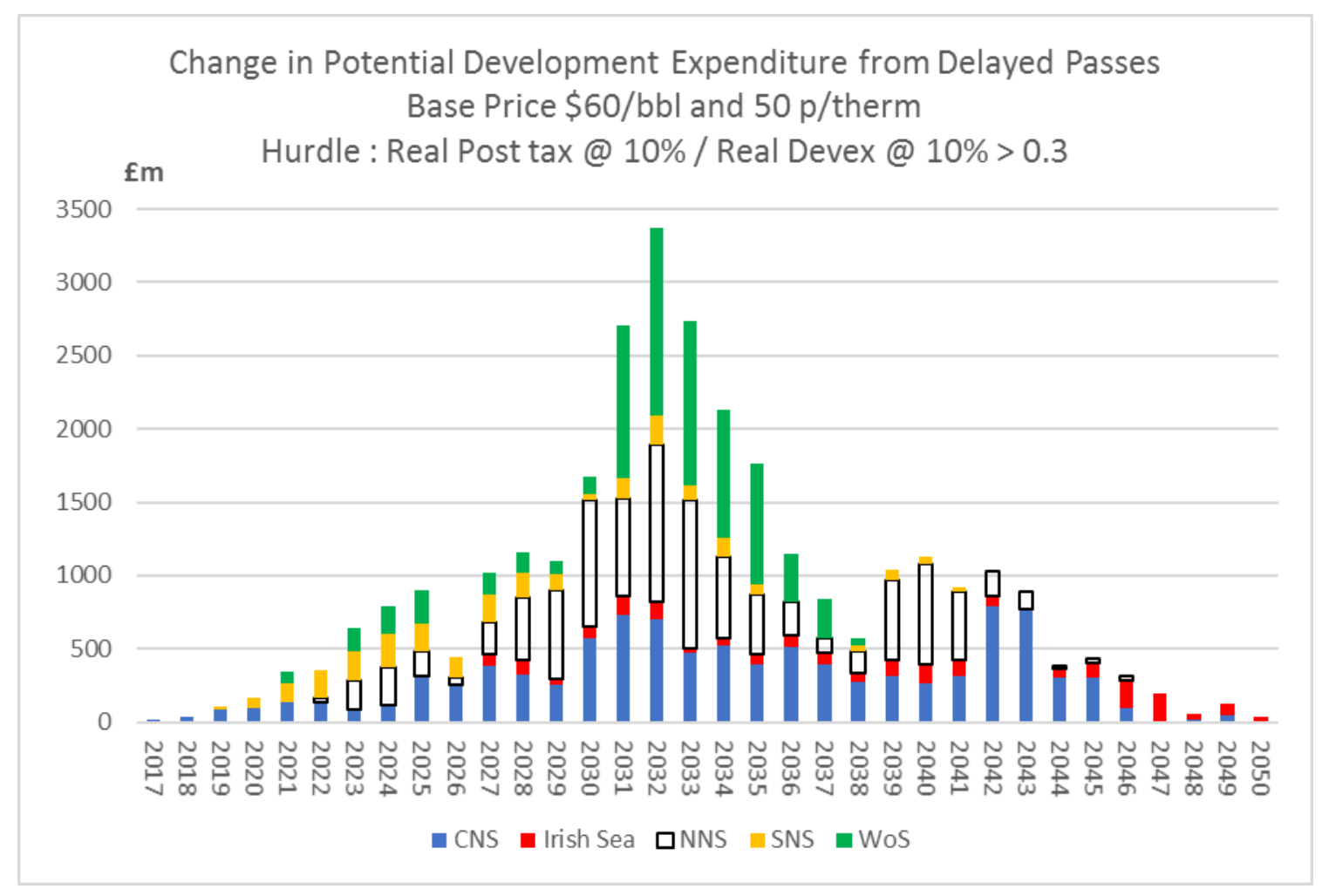




\section{(g) Operating Expenditure}

The total operating expenditures over the period to 2050 are shown in Chart 19. Under the $\$ 60,50$ pence prices scenario the aggregate amounts to $£ 123.7 \mathrm{bn}$. The total extra induced by the rising price scenario is $£ 71.3 \mathrm{bn}$. Of this latter total $£ 47.7$ bn emanates from new field and project passes. Delayed field passes contribute $£ 18.7 \mathrm{bn}$.

The field life extension effect is shown in Chart 20. It adds $£ 4.9$ bn to operating expenditures of which $£ 3.2$ bn comes from sanctioned fields and $£ 0.9$ bn from new discoveries. Of the total $£ 2.2$ bn is in the CNS, $£ 1.3$ bn in the NNS, and $£ 1$ bn in the W of S (Chart 21).

Chart 19

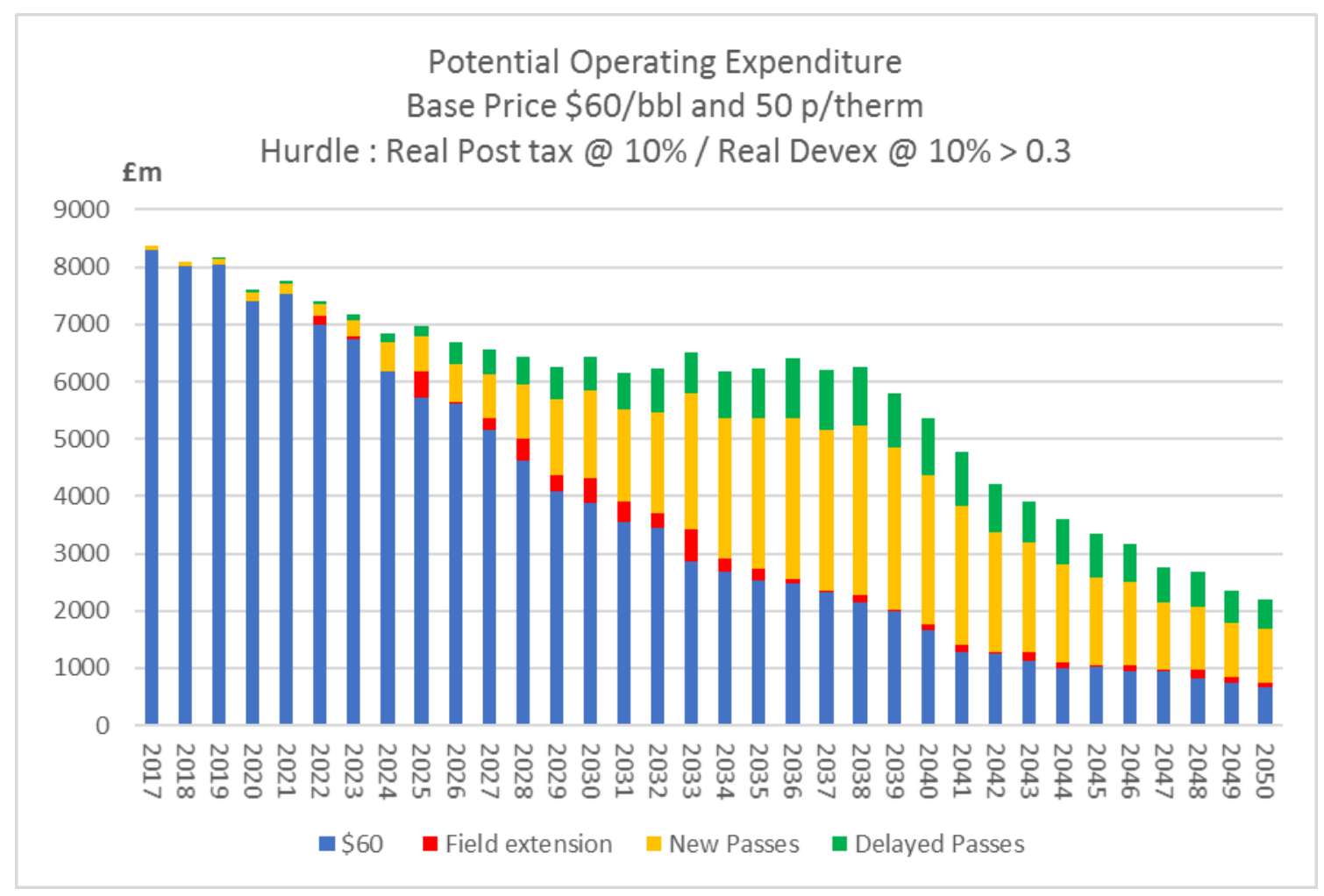


Chart 20

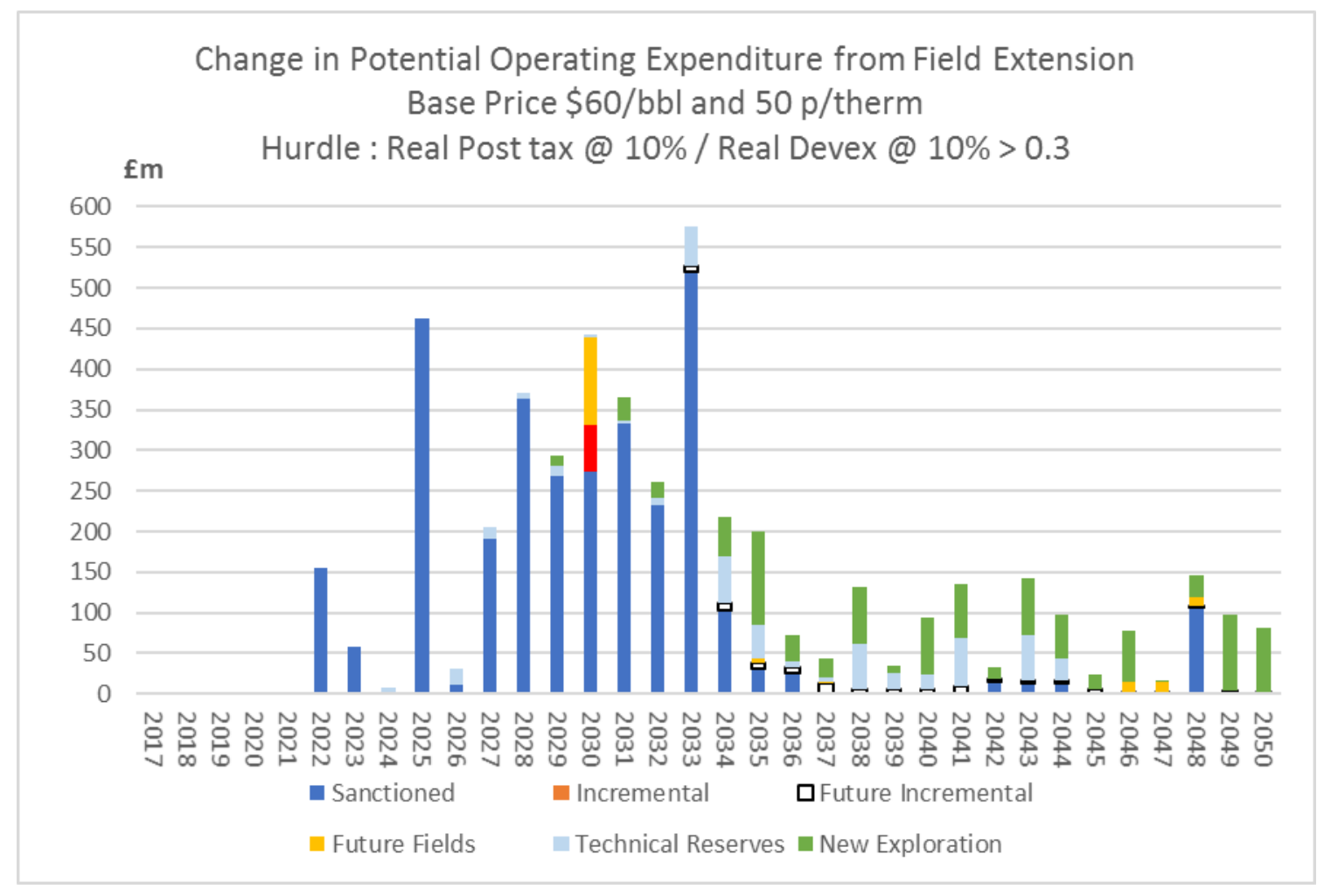

Chart 21

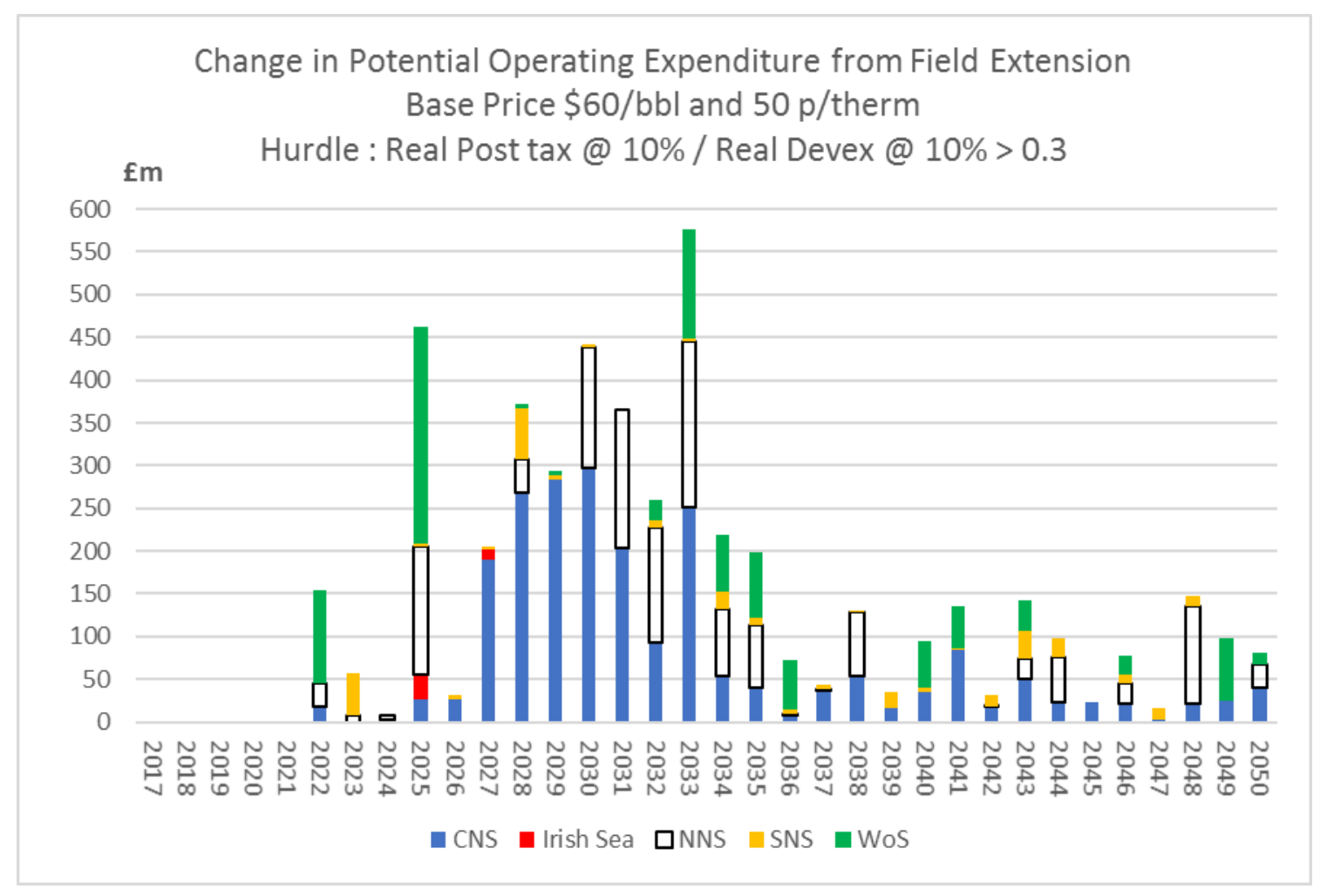


The increase in operating expenditures on fields and projects in the new passes category are shown in Chart 22 . Of the total of $£ 47.7$ bn probable and possible fields contribute $£ 8.6$ bn, technical reserves $£ 30$ bn, new discoveries $£ 6.1$ bn, and current plus future incremental projects $£ 3.1$ bn. Geographically, $£ 21.3$ bn occurs in the $\mathrm{W}$ of $\mathrm{S}, £ 15.6$ bn in the CNS, $£ 7.5$ bn in the NNS, and $£ 3.2$ bn in the SNS (Chart 23).

\section{Chart 22}

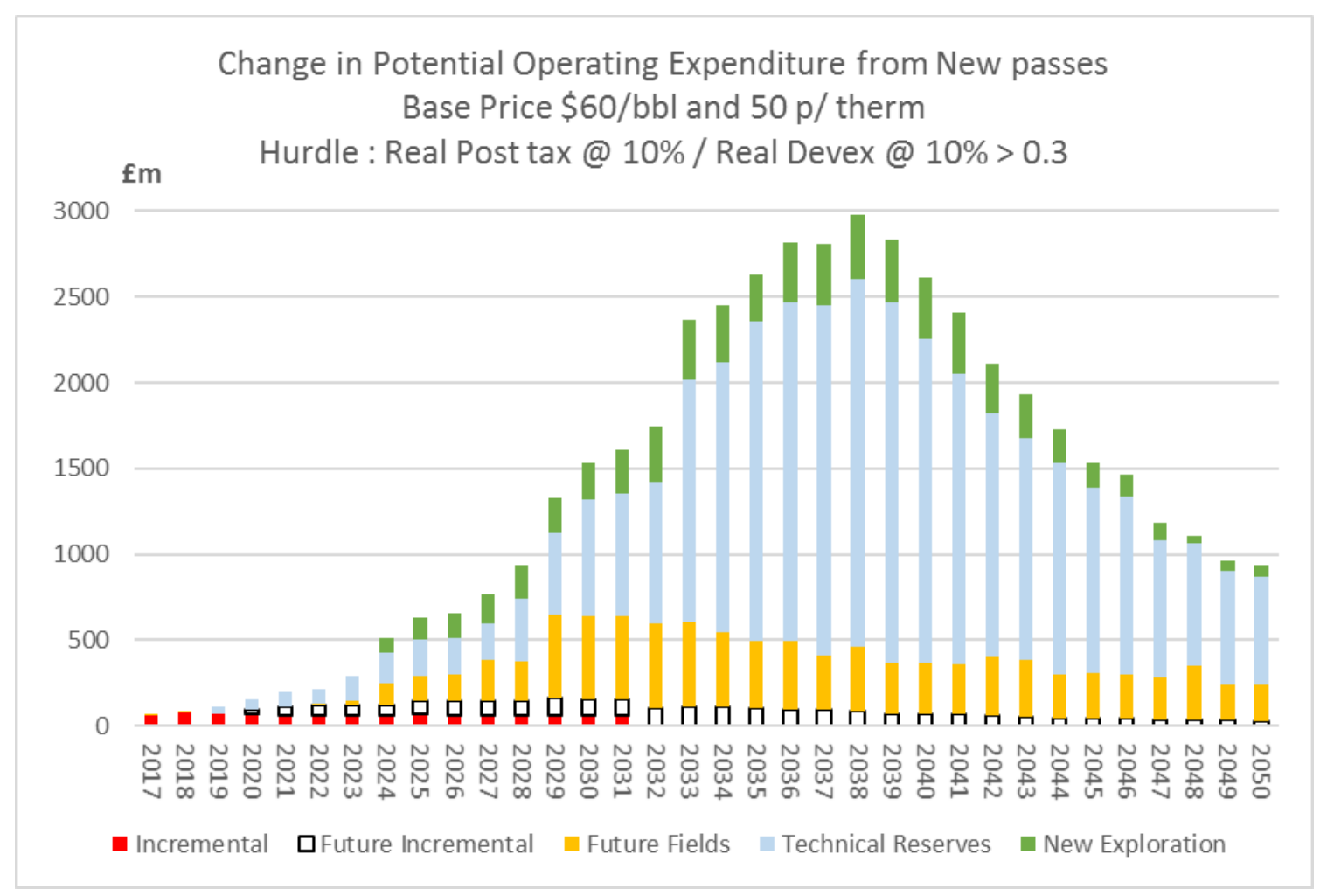


Chart 23

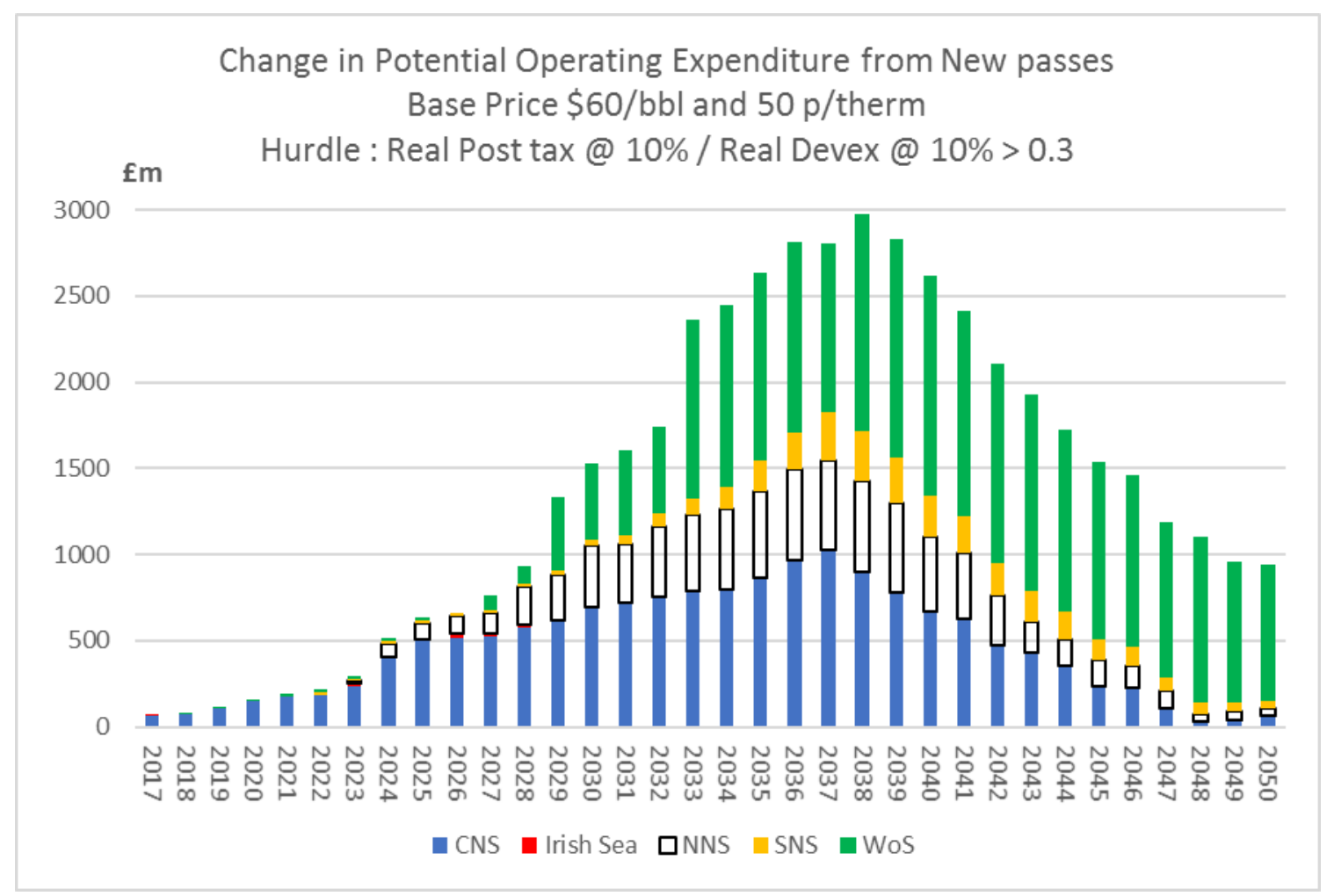

In Chart 24 the extra operating expenditures on fields in the delayed passes category are shown. The total is $£ 18.7$ bn over the period. Of this probable and possible fields contribute $£ 6$ bn, technical reserves $£ 11.6 \mathrm{bn}$, and new discoveries $£ 1.1 \mathrm{bn}$. Of the total of $£ 18.7 \mathrm{bn}, £ 6.7$ bn occurs in the CNS, $£ 6.1$ bn in the NNS, $£ 4.5$ bn in the $\mathrm{W}$ of $\mathrm{S}$, and $£ 0.9$ bn in the SNS (Chart 25). 


\section{Chart 24}

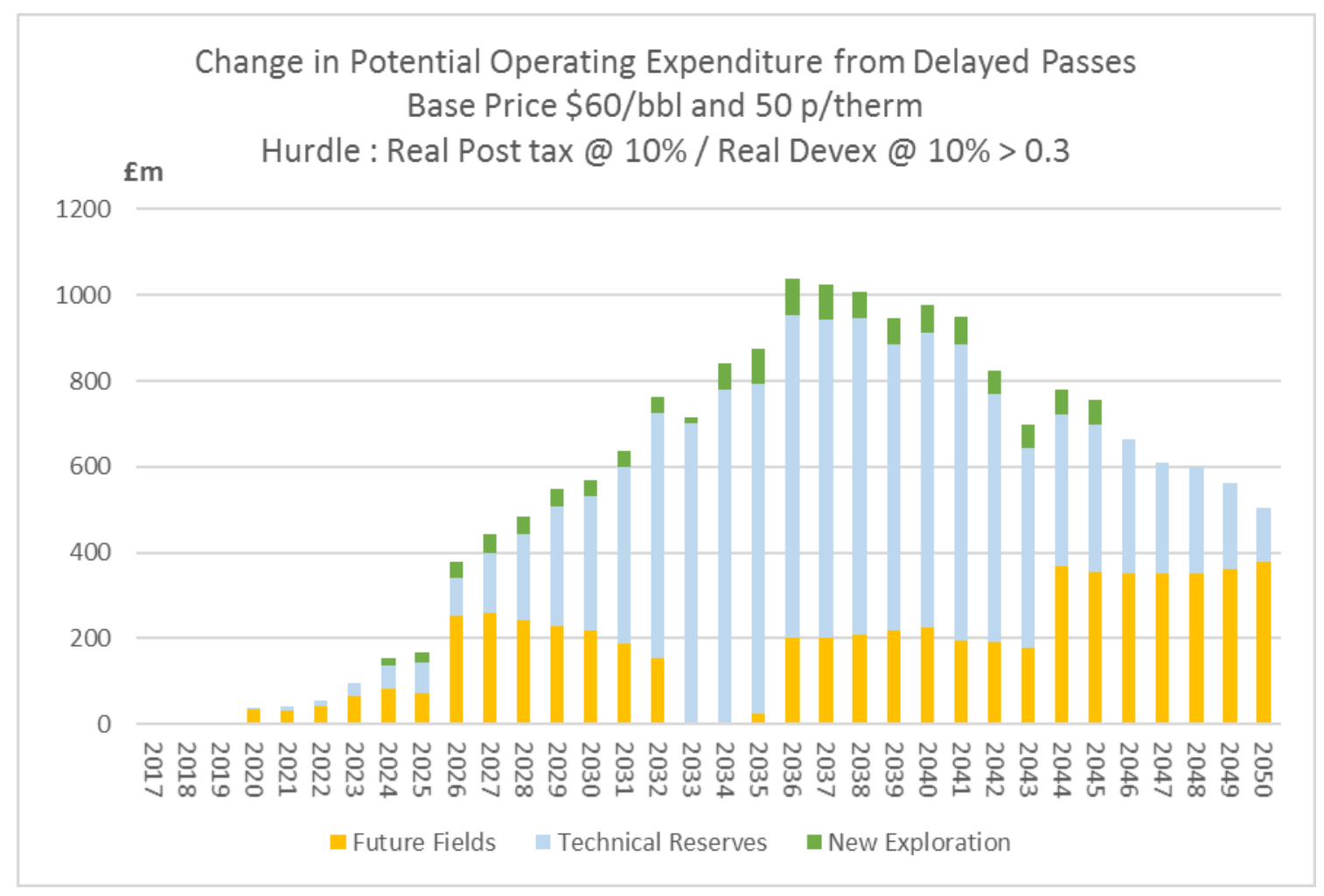

Chart 25

Change in Potential Operating Expenditure from Delayed Passes

Base Price $\$ 60 / \mathrm{bbl}$ and $50 \mathrm{p} /$ therm

$\mathbf{f m}$

Hurdle : Real Post tax @ 10\% / Real Devex @ 10\% $>0.3$

1200

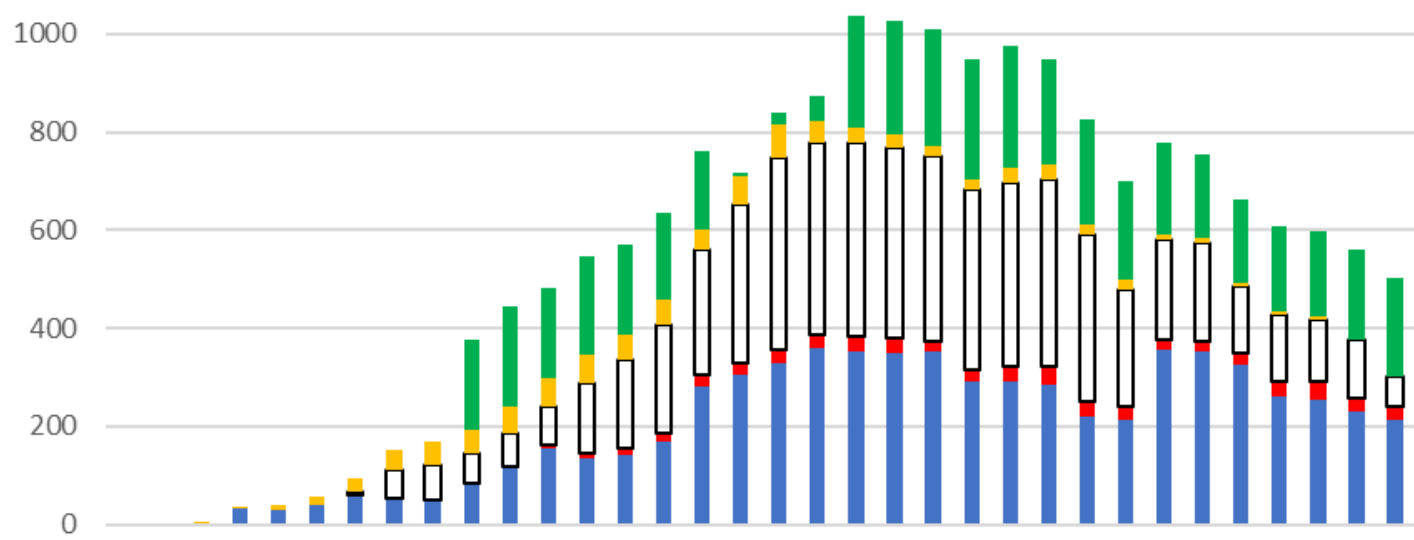

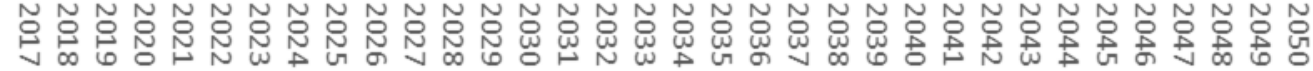

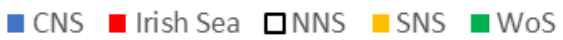




\section{(h)Decommissioning Expenditure}

Decommissioning expenditure in the period to 2050 is shown in Chart 26. Under the $\$ 60,50$ pence scenario the total is $£ 54.2$ bn at 2017 prices. The net effect of the rising price scenario is to increase the total cost to 2050 by $£ 6.1 \mathrm{bn}$. This is the combined effect of an increase of $£ 4$ bn on fields and projects in the new passes category, an increase of $£ 2.2$ bn on fields in the delayed passes category, and a decrease of $£ 0.2$ bn in field life extension cases. This last effect causes field lives to be extended, resulting in reductions in decommissioning activity in some years and increased activity in later years. This also means that some decommissioning activity is postponed beyond the year 2050. Modelling beyond this year reveals that even by 2060 the field extension effect of the higher price is to reduce decommissioning expenditures by $£ 34$ million.

Chart 26

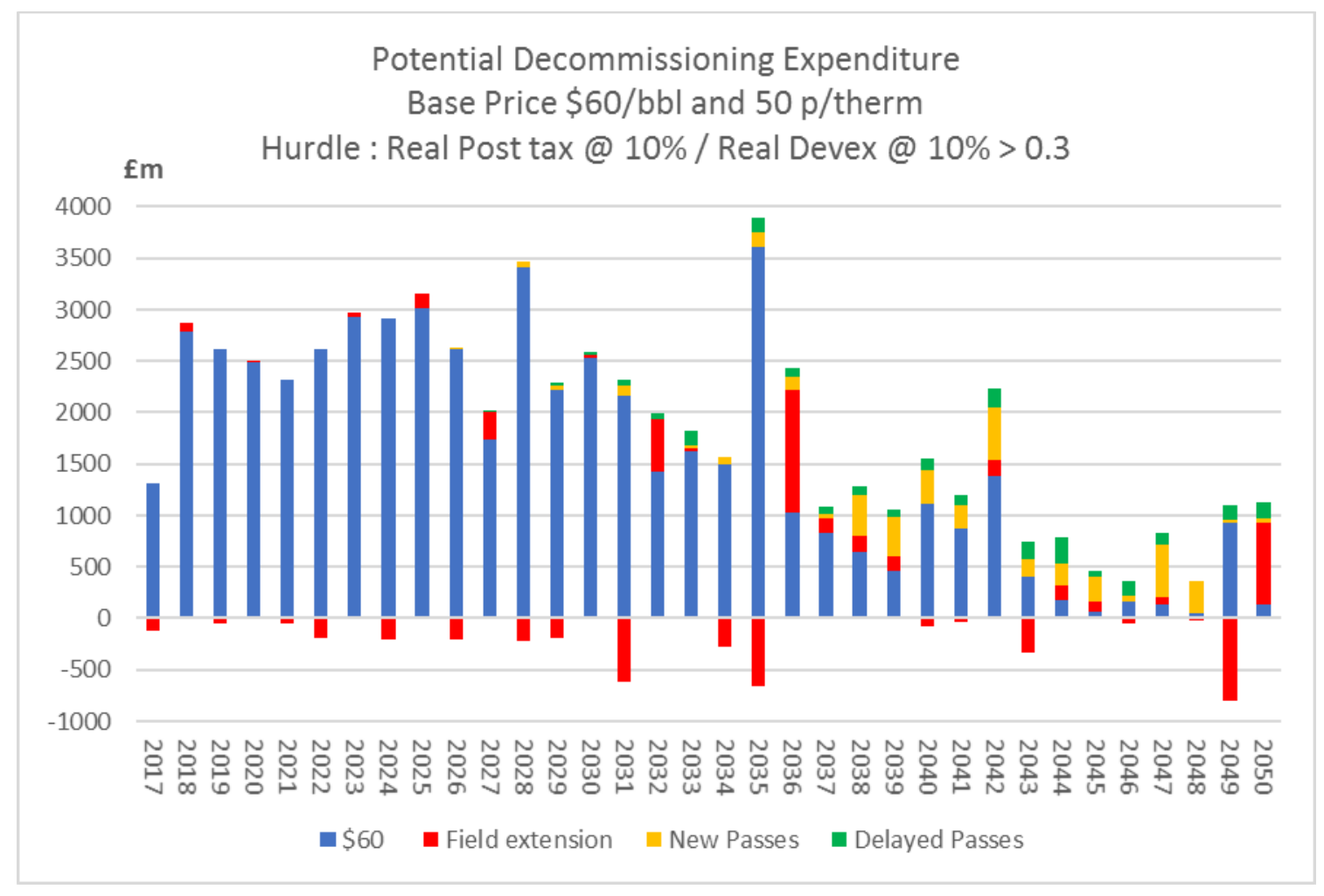


In Charts 27 and 28 the effects of field life extensions are shown for the different categories of fields and geographic areas of the UKCS. Decreases followed by increases are a main finding.

\section{Chart 27}

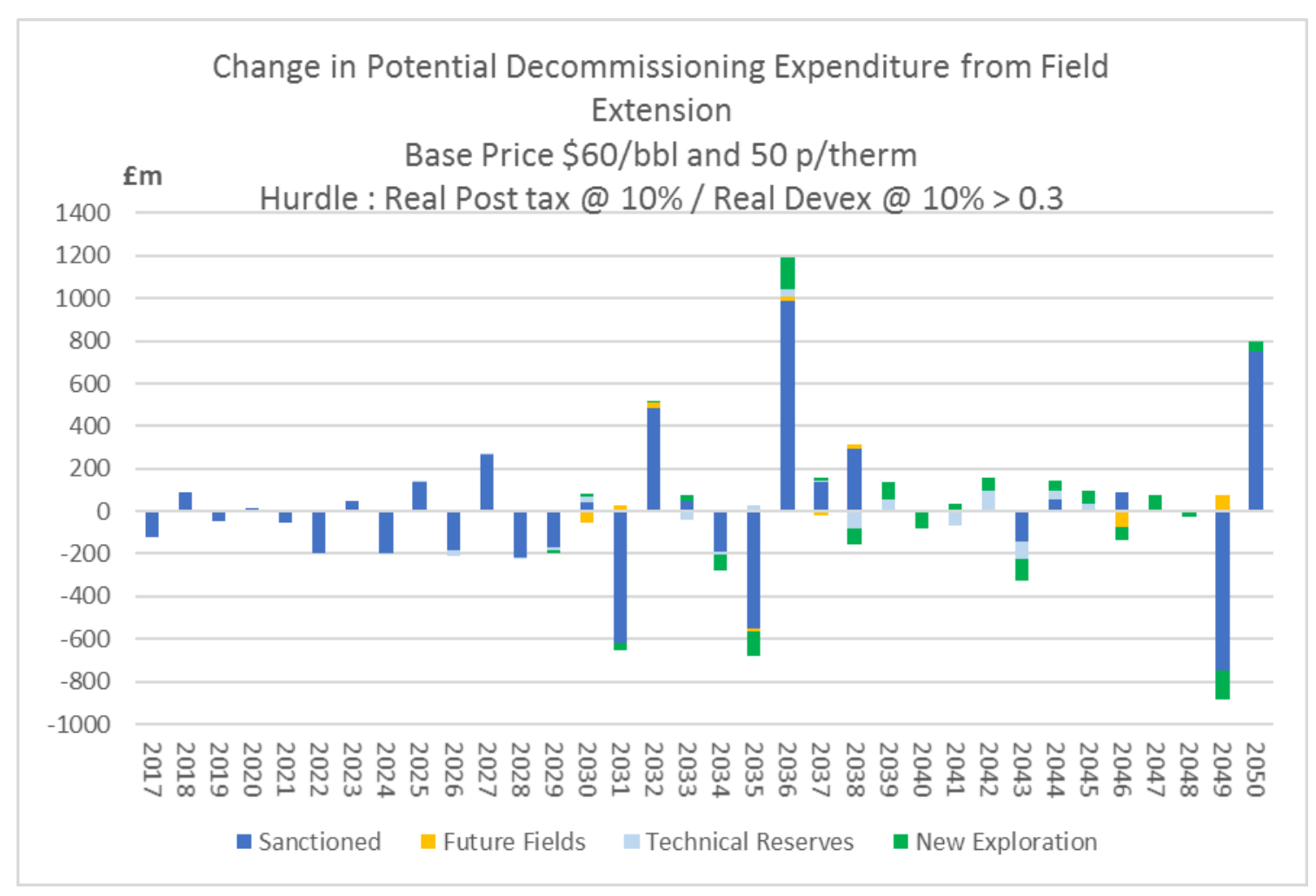


Chart 28

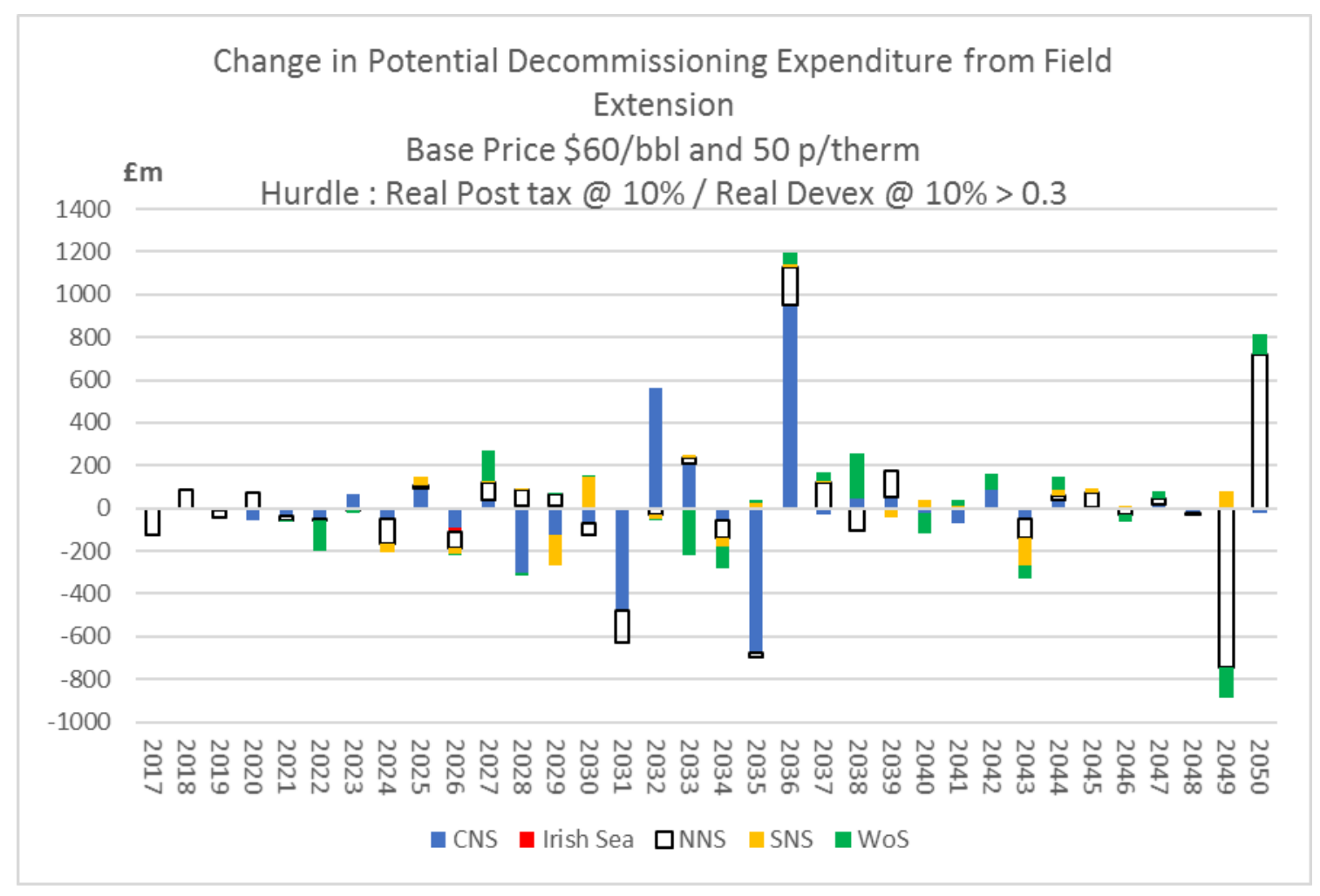

In Charts 29 and 30 the changes to decommissioning expenditure from the development of fields in the new passes category are shown. The overall effect is to increase decommissioning activity by $£ 4$ bn in the period to 2050. The development of more probable and possible fields contributes $£ 0.5$ bn, while the development of fields in the category of technical reserves contributes $£ 2.8$ billion. New discoveries contribute $£ 0.7$ bn. Geographically, the main increase is in the CNS where nearly $£ 2$ bn extra is spent on decommissioning. 
Chart 29

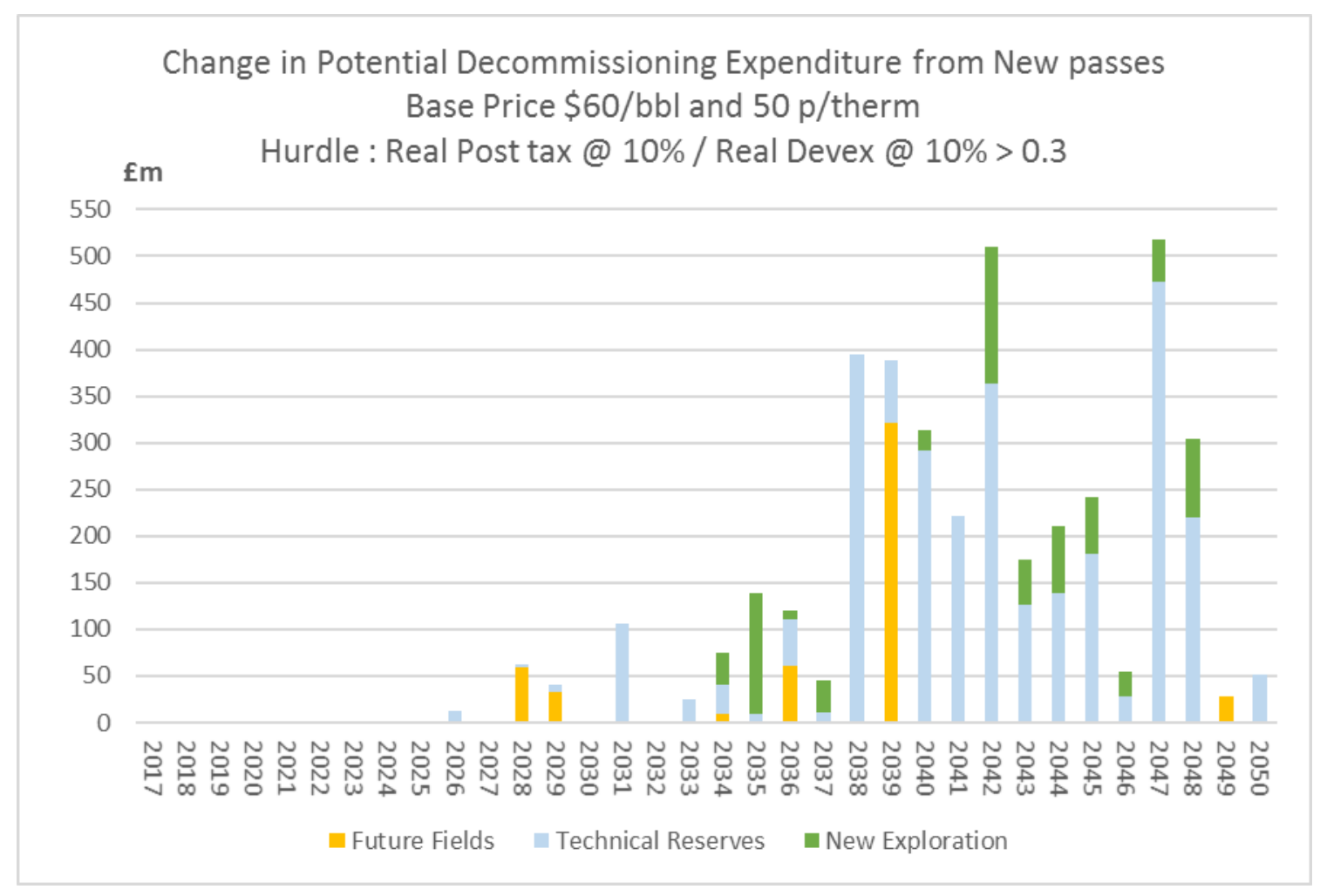

Chart 30

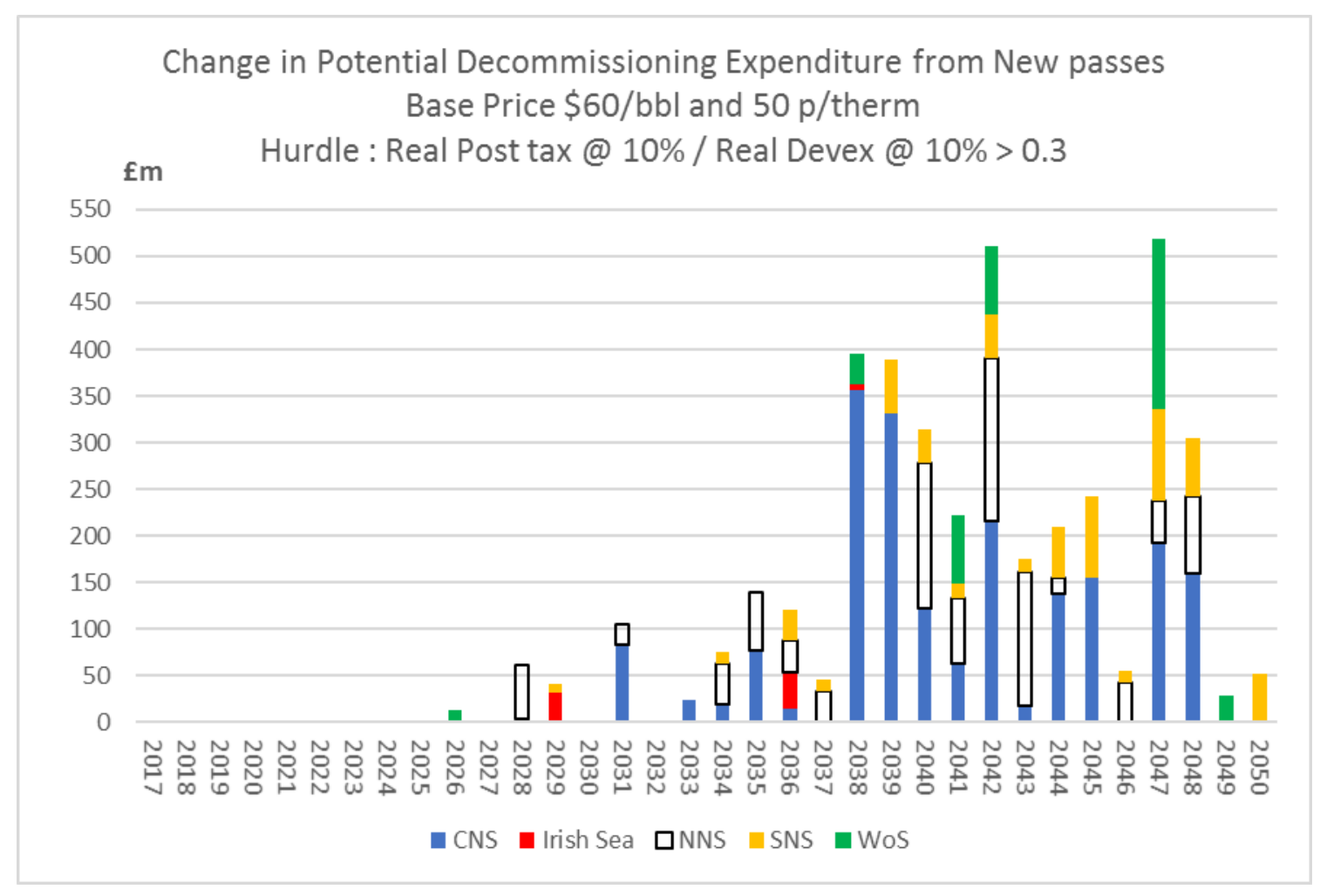


In Charts 31 and 32 the changes to decommissioning expenditure on fields in the delayed passes category are shown. There is a total increase of $£ 2.2$ bn in the period to 2050 . Of that there is a contribution of $£ 0.24$ bn on probable and possible fields, $£ 1.8$ bn on fields in the category of technical reserves, and $£ 0.2$ bn on new discoveries. Around $£ 0.8$ bn is in the CNS, $£ 0.8$ bn in NNS, $£ 0.2$ bn in $\mathrm{W}$ of $\mathrm{S}$, and $£ 0.25$ bn in the SNS.

\section{Chart 31}

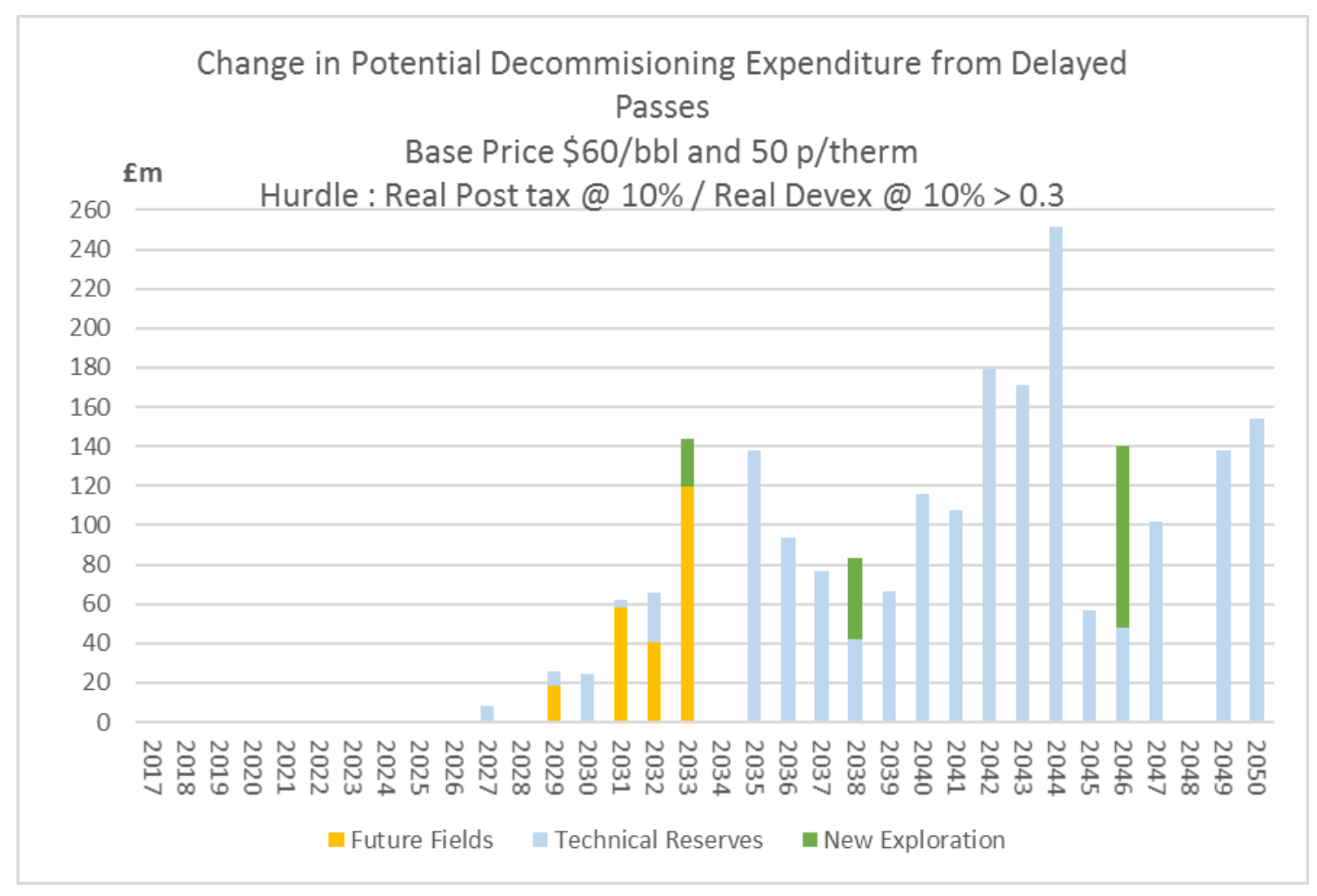


Chart 32

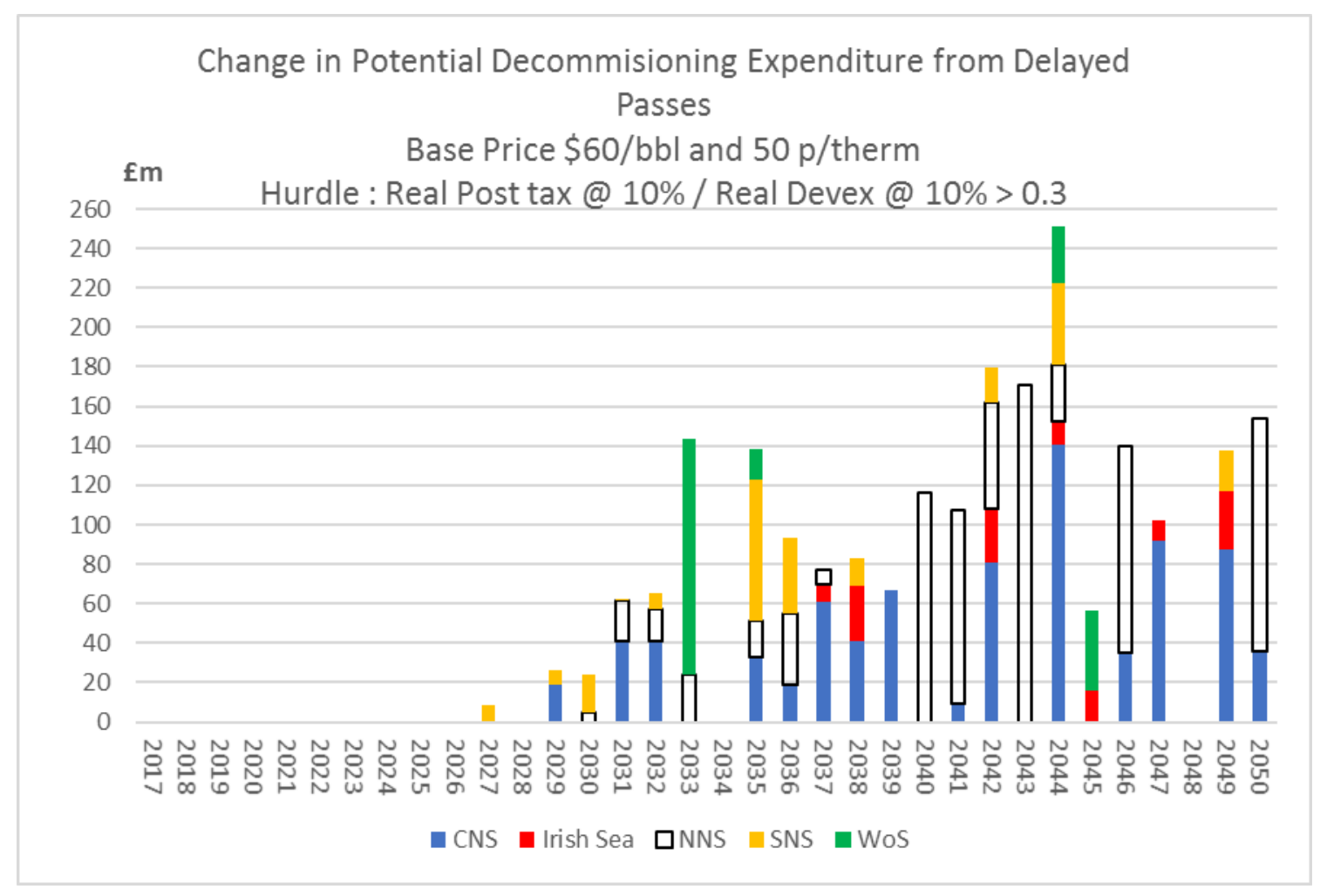

\section{Conclusions}

Projecting long term activity levels in the UKCS has always been difficult, and previous studies by reputable organisations have often turned out to be inaccurate, sometimes by considerable margins. For example, as late as 1988 it was confidently predicted that oil production would continue its downward path from its peak achieved in 1984. The vigorous increase to a new peak in 1999 was not foreseen. In 1999 the Industry-Government Task Force set an aspirational target of production of 3 million boe/d for 2010. Sadly, the outturn was around $2.4 \mathrm{mmboe} / \mathrm{d}$, even though oil prices had increased much further than would have been believed likely in 1999 .

The projections made in this paper are not forecasts. They are designed to build a scenario which indicates that long term activity could be significantly higher than the projections currently deemed most likely 
(including by the present authors). Oil prices have proved notoriously unpredictable in the past, and even their direction has often been wrongly predicted. A (real) price of $\$ 100$ by 2050 is consistent with at least some long term projections by reputable organisations and should not be regarded as very unlikely.

While such a price scenario is probably necessary to significantly enhance activity in the UKCS, it is not a sufficient condition. To obtain maximum benefit it is argued that effective cost control, technological progress, and collaboration are also necessary to achieve maximum benefits and to achieve MER UK. If costs (per boe) were to increase along with the oil price the potential benefits would be negated, at least in part, and the new investments would not occur on the scale necessary to achieve a high activity rate. Technical progress should be geared in large part to reducing investment and operating costs on the many small, undeveloped fields. The study shows that this is by far the greatest gain which can be made to MER UK and particularly to the supply chain. The supply chain's scale would be maintained at levels which would keep it anchored to the UK for many years and facilitate its effective competition in export markets.

For the longer term a further lesson of the research paper is that, if economic recovery is to be higher than c. 16 bn boe (which is consistent with the present study) the exploration effort will have to be increased well above the levels which are currently predicted. 